\title{
Rgma-Induced Neo1 Proteolysis Promotes Neural Tube Morphogenesis
}

\author{
Sharlene Brown, ${ }^{\star}$ Pradeepa Jayachandran, ${ }^{\star}$ Maraki Negesse, Valerie 0lmo, Eudorah Vital, and $๑$ Rachel Brewster \\ Department of Biological Sciences, University of Maryland Baltimore County, Baltimore, Maryland 21250
}

Neuroepithelial cell (NEC) elongation is one of several key cell behaviors that mediate the tissue-level morphogenetic movements that shape the neural tube (NT), the precursor of the brain and spinal cord. However, the upstream signals that promote NEC elongation have been difficult to tease apart from those regulating apico-basal polarity and hingepoint formation, due to their confounding interdependence. The Repulsive Guidance Molecule a (Rgma)/Neogenin 1 (Neo1) signaling pathway plays a conserved role in NT formation (neurulation) and is reported to regulate both NEC elongation and apico-basal polarity, through signal transduction events that have not been identified. We examine here the role of Rgma/Neo1 signaling in zebrafish (sex unknown), an organism that does not use hingepoints to shape its hindbrain, thereby enabling a direct assessment of the role of this pathway in NEC elongation. We confirm that Rgma/Neo1 signaling is required for microtubule-mediated NEC elongation, and demonstrate via cell transplantation that Neo1 functions cell autonomously to promote elongation. However, in contrast to previous findings, our data do not support a role for this pathway in establishing apical junctional complexes. Last, we provide evidence that Rgma promotes Neol glycosylation and intramembrane proteolysis, resulting in the production of a transient, nuclear intracellular fragment (NeoICD). Partial rescue of Neola and Rgma knockdown embryos by overexpressing neoICD suggests that this proteolytic cleavage is essential for neurulation. Based on these observations, we propose that RGMA-induced NEO1 proteolysis orchestrates NT morphogenesis by promoting NEC elongation independently of the establishment of apical junctional complexes.

Key words: cell elongation; microtubules; neogenin; neural tube; regulated intramembrane proteolysis; Rgma

Significance Statement

The neural tube, the CNS precursor, is shaped during neurulation. Neural tube defects occur frequently, yet underlying genetic risk factors are poorly understood. Neuroepithelial cell (NEC) elongation is essential for proper completion of neurulation. Thus, connecting NEC elongation with the molecular pathways that control this process is expected to reveal novel neural tube defect risk factors and increase our understanding of NT development. Effectors of cell elongation include microtubules and microtubuleassociated proteins; however, upstream regulators remain controversial due to the confounding interdependence of cell elongation and establishment of apico-basal polarity. Here, we reveal that Rgma-Neo1 signaling controls NEC elongation independently of the establishment of apical junctional complexes and identify Rgma-induced Neol proteolytic cleavage as a key upstream signaling event.

\section{Introduction}

The CNS derives from the neural tube (NT) that is formed during neurulation. Hallmarks of primary neurulation include the

Received Dec. 30, 2018; revised July 1, 2019; accepted July 31, 2019.

Author contributions: S.B., P.J., V.O., and R.B. designed research; S.B., P.J., M.N., V.O., and E.V. performed research; S.B., P.J., and R.B. contributed unpublished reagents/analytic tools; S.B., P.J., M.N., V.O., E.V., and R.B. analyzed data; S.B., P.J., and R.B. wrote the first draft of the paper; S.B., P.J., M.N., V.O., and R.B. edited the paper; S.B., P.J., and R.B. wrote the paper.

This work was supported by National Institutes of Health/National Institute of General Medical Sciences Grant GM085290-02S1 to V.0. and Grant GM085290 to R.B. S.B. was supported by a U.S. Department of Education GAANN Fellowship, Grant P200A120017, and National Institutes of Health/National Institute of General Medical Sciences Grant GM055036 (Meyerhoff Graduate Fellowship). M.N. was supported by National Institute of General Medical Sciences/National Institutes of Health T32 GM066706, National Science Foundation 1500511, and National Institutes of Health/National Institute of General Medical Sciences GM055036. E.V. was supported by Howard Hughes thickening of the neural plate (NP), narrowing and lengthening of the NP, elevation of the lateral borders of the NP to form neural folds, fusion of the neural folds at the dorsal midline, and separation of the neural folds from the overlying non-neural ec-

Medical Institute (Precollege and Undergraduate Science Education Program) Grant 52008090 to University of Maryland Baltimore County. The SP5 confocal microscope (Leica Microsystems) was purchased with funds from the National Science Foundation Grant DBI-0722569. We thank Robyn Goodman for cell transplantation experiments; and Neus Sanchez-Alberola, Julie Wolf, Yiannis Balanos, and Nilusha Jayasinghe for contributions to CRISPR/Cas9 tools.

The authors declare no competing financial interests.

*S.B. and P.J. contributed equally to this work.

Correspondence should be addressed to Rachel Brewster at brewster@umbc.edu.

https://doi.org/10.1523/JNEUROSCI.3262-18.2019

Copyright $\odot 2019$ the authors 
toderm (Colas and Schoenwolf, 2001). Significant inroads have been made into understanding the cellular basis of these tissuelevel changes; however, connecting specific cellular behaviors to the signaling pathways that control them has proven more challenging.

The zebrafish is ideally suited to study the cellular basis of morphogenesis because of the early accessibility and transparency of its embryo. Despite its mesenchymal-like appearance, the zebrafish NP is shaped into a tube by organized epithelial infolding, akin to primary neurulation (Papan and CamposOrtega, 1994). The transient structure formed by infolding, termed the neural keel, becomes a solid neural rod by midsomitogenesis and matures into a NT with a clearly defined midline and lumen following cavitation (Papan and Campos-Ortega, 1994).

During neurulation, cells undergo significant changes in shape, from cuboidal to columnar, as they elongate along their apico-basal axis (Schroeder, 1970; Burnside, 1971; Karfunkel, 1974; Schoenwolf and Franks, 1984). Cell elongation is required for thickening the NP of amniotes, resolving the bilayered NP of zebrafish and Xenopus embryos into a monolayered neuroepithelium via radial intercalation (Hong and Brewster, 2006; Kee et al., 2008) and elevating the neural folds, in absence of which the NT fails to close (Karfunkel, 1971, 1972; Suzuki et al., 2012). Apical constriction, another essential cell behavior, causes neuroepithelial cells (NECs) to adopt a wedge shape (Suzuki et al., 2012), resulting in the formation of one median and two dorsolateral hingepoints (Shum and Copp, 1996), around which the NP of amniotes bends and folds.

The upstream signaling events that control NEC elongation are not well understood. In a landmark study (Kee et al., 2008), Rgma and its receptor Neol were identified as upstream regulators of NEC elongation and establishment of apico-basal polarity. However, the interdependence of both of these processes in Xenopus (Suzuki et al., 2012) prevented a direct assessment of the role of Rgma-Neo1 signaling in controlling either process.

neol encodes a transmembrane receptor belonging to the immunoglobulin superfamily. Repulsive guidance molecules are a family of glycosylphosphatidylinositol-anchored proteins that function as membrane-bound, short-range guidance cues or as secreted, long-range signals (Tassew et al., 2012). Rgma-Neol signaling plays a conserved role in neurulation, as knockdown of the ligand and/or receptor prevents NT closure in mice (Niederkofler et al., 2004) and Xenopus (Kee et al., 2008). The signaling events activated downstream of Rgma-Neol interaction that promote cell elongation and NT closure are currently unknown; however, previous studies have identified several putative signaling mechanisms. Both Rgma and Neol are known to modulate bone morphogenetic protein signaling (Babitt et al., 2005; Zhou et al., 2010; Tian and Liu, 2013). Repulsive guidance molecules can also directly bind to Neo1, triggering structural changes to the actin cytoskeleton through the Rho family of small guanosine-5'triphosphate-hydrolyzing GTPases (Hata et al., 2006; Conrad et al., 2007). Furthermore, Neo1 is sequentially cleaved by $\alpha$ - and $\gamma$-secretases in response to Rgma binding, leading to the release of a Neol intracellular domain (NeoICD) that regulates transcription (Goldschneider et al., 2008; van Erp et al., 2015). Neo1 proteolytic cleavage has been implicated in axonal pathfinding and neuronal migration (van Erp et al., 2015; Banerjee et al., 2016).

In zebrafish embryos, NEC elongation precedes the establishment of apical junctional complexes (Hong and Brewster, 2006), making it an ideal model for teasing apart the signals required for cell elongation specifically. This study aims to determine the role of Rgma-Neo1 in NEC elongation and to identify the signal transduction events triggered by ligand-receptor interaction that impinge on neurulation.

\section{Materials and Methods}

Husbandry, care, and use of zebrafish

WT zebrafish (Danio rerio) of the AB strain were reared and manipulated using protocols approved by the Institutional Animal Care and Use Committee at the University of Maryland Baltimore County. Fish were maintained in UV-irradiated, filtered running water and exposed to 14:10 light/dark cycle. Male and female fish were separated by a partition that was removed after first light to initiate spawning of fry (embryos). Embryos were collected and staged according to previously described methods (Kimmel et al., 1995). The sex of the embryos used is unknown.

\section{Construction of dominant-negative neola plasmid}

Custom-made neola ${ }^{\delta 1133-F L A G}$ (GenScript) was modeled after a previously published dominant-negative neol construct used in Xenopus (Kee

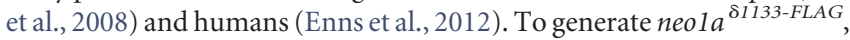
a partial zebrafish neola coding sequence (Accession no. Q8AY67) was subcloned from pUC57 into the pCS2 ${ }^{+}$vector. This insert encodes a mutant form of neola lacking the $\mathrm{C}$ terminal region and spans amino acids 1-1132. This sequence is immediately followed by one corresponding to a single C-terminal FLAG epitope tag (5' -GACTACAAAGACGAT GACGACAAG-3') (inserted after base pair 3397, corresponding to amino acid residue 1132), a translation termination sequence (TGA), and the full 3' UTR and poly A tail (pA) of neola (Accession no. Q8AY67). For efficient in vitro transcription, the T7 promoter was introduced at the $5^{\prime}$ end of the insert followed by a 10-mer poly-thymine spacer. A SnaBI restriction site (TACGTA) was added 3' to the neola pA just before the SV40 pA signal of the pCS2 ${ }^{+}$vector to provide a unique site for linearization of the vector before transcription.

\section{Construction of mutant NeoICD plasmid}

The nuclear localization sequence of NeoICD corresponds to the $\mathrm{N}$ terminal region of the ICD and has the following peptide sequence: RRTTTQQKKKR. To generate a peptide that fails to localize to the nucleus, the pCS2 ${ }^{+}$plasmid containing neoICD-6x myc (GenScript) was mutated to include two substitutions respective to full-length Neola, R1123A/R1124A, generating the mutant peptide sequence AATTTQQK KKR (designed based on Goldschneider et al., 2008). The resultant mutant construct was named neoICD $D^{\mathrm{R} 1123 \mathrm{~A} / \mathrm{R} 1124 \mathrm{~A}}-6 x$ myc $\left(\right.$ neoICD $\left.{ }^{\text {mut }}\right)$.

\section{Morpholino (MO)-mediated Rgma and Neola knockdown}

MOs. MOs were commercially obtained (Gene Tools) and administered at $5 \mathrm{ng} / \mathrm{embryo}$, with the exception of one Western blot assay as indicated in Results. Each MO was injected at the 1-4 cell stages into the yolk margin just underneath the embryo proper. The MO sequences are as follows: rgma 5'UTR MO1: 5'-ACACTTTTGGGTTGAGTTTCTTT TTGC-3' (Gibert et al., 2011); rgma AUG MO2: 5' -CTCTCCTCTCCC TTTTTGAATGCAT-3'; neola AUG MO2: 5'-GGCTCCCCGCT CCGCCATCACTTTA-3' (Mawdsley et al., 2004); and standard control MO (std MO): 5'-CCTCTTACCTCAGTTACAATTTATA-3' (Schmajuk et al., 1999). neo 1a MO2 is complementary to 25 and 19 consecutive bases of neola and neolb, respectively.

Dominant-negative neola and neoICD. Dominant-negative $\left(\right.$ neola $\left.{ }^{\text {S1133-FLAG }}\right)-$ pCS2 ${ }^{+}$plasmid was linearized with SnaBI (NEB) and in vitro transcribed with T7 polymerase using the T7 mMESSAGE mMACHINE kit (Ambion, catalog \#AM1344), according to the manufacturer's guidelines for GC-rich templates; 120 pg of column-purified neo1 $a^{\text {S1133-FLAG }}$ mRNA was injected into the cytoplasm of 1-4 cell stage embryos.

The coding sequence corresponding to the $981 \mathrm{bp}$ intracellular domain of zebrafish neola (neoICD) was amplified from the full-length Neola subcloned into $\mathrm{pCS}^{+}{ }^{+}$vector (GenScript) containing full-length neola coding sequence to produce a DNA template using the following primers: T7-neoICD forward: 5'-TAATACGACTCACTATAGggAT GCTTTGTACACGTCGTACCACA-3'; and neoICD reverse: 5'-TCA 
GGCTGTTGTGATGGC-3'. PCR products were transcribed using T7 mMessage Machine kit (Ambion); 50 pg of column-purified neoICD mRNA was injected.

\section{CRISPR/Cas9-induced rgma and neola indels}

Target selection. The online bioinformatics tool CHOPCHOP (Montague et al., 2014; Labun et al., 2016) was used to identify unique CRISPR targets for rgma (Ensembl reference number ENSDARG00000012248 from the zebrafish genome reference consortium assembly 9 [GRCz9]) and neola (ENSDARG00000102855 from the GRCz10 and GRCz11, NM_173218.2). Each guide RNA (gRNA) target sequence was chosen for its lack of homology to other sequences in the published zebrafish genome, predicted off-target effects, and self-complementation. The CRISPR target sequences are as follows: rgma exon 2: 5'-GGTGTA AATAGGGAGAGGAG-3'; rgma exon 3: 5'-GGTGGGACTGTGCGG GCACG-3'; neola exon 3: 5'-CCGCTGGGAACAGAATAAAG-3'; neola exon 3: 5' -CTAATGCCAGGCTCCAGAGG-3'; neo $1 b$ exon 3: 5' GAGGGTGTTTCTGTTCGCAG-3'; and neo $1 b$ exon 8: 5'-AGAGA CGCCACCACATCCCG-3' .

Generation of insertion-deletions (indels). Embryos were mutagenized by active ribonucleoproteins consisting of the Alt-R CRISPR/Cas9 highfidelity nuclear-targeted Cas9 protein (HF-nCas9) and exon-specific gRNAs according to the manufacturer's recommendations (IDT) (Kim et al., 2014; Burger et al., 2016; Anderson et al., 2017, 2018). Ribonucleoproteins were injected individually or multiplexed to target multiple exons. Early 1 cell stage embryos were injecting with 3 pmol of each gRNA and 0.5 ng of HF-nCas9.

High-resolution melt analysis. Genomic DNA (gDNA) extractions from individual embryos were prepared by alkaline lysis (Meeker et al., 2007), separated from particulates via centrifugation, and diluted 1:100 to be used as PCR templates. SYBR Green qPCR was performed using Precision Melt Supermix (Bio-Rad) according to the manufacturer's suggestions. The following primer sets were used to amplify gDNA for 40 cycles as follows: rgma exon 2 forward: 5'-CACGCAGAGTACCTGA CAAAAG-3'; rgma exon 2 reverse: 5'-AAGGAACTGGCAGACTTG TAGC-3'; rgma exon 3 forward: 5'-AGAAGAGGAGTTTTGCACT GCT-3'; rgma exon 3 reverse: 5' -TATGTGGTAGACTCCGCTCGTA-3'; neo $1 a$ exon 3 forward: 5' -CTTGCACAAAAAGTGGAACAAT-3'; neo1a exon 3 reverse: $5^{\prime}$-GTCTGTCTCTGTGGCGTTACTG-3'; neo $1 a$ exon 8 forward: $5^{\prime}$-CGTCACCCTACTGTCTTCACTG-3'; neola exon 8 reverse: $5^{\prime}$-TATTAATGTGACGTAGGTGCCC-3'; neo $1 b$ exon 3 forward: $5^{\prime}$-TGGTTTTCTGTAGTAACGCAGC-3'; neo $1 b$ exon 3 reverse: $5^{\prime}$-TC TATGGTGCAACGGTAGAGTC-3'; neo $1 b$ exon 8 forward: 5' -CTACT GACCATGTAGCGTCCAG-3'; and neo $1 b$ exon 8 reverse: $5^{\prime}$-TAG TGCCGTCCAGACTGTAGAA-3'.

Amplification and melt analysis at $0.2^{\circ} \mathrm{C}$ increments were performed on a CFX96 real-time system with C1000 cycler (Bio-Rad). Baseline normalization and difference curves were obtained by thresholding and processing the melt RFU data using uAnalyze (https://dna.utah.edu/uv/ uanalyze.html). Melting point homogeneity and heterogeneity were expected among PCR products derived from WT and mosaic mutant embryos, respectively.

\section{Microinjections of $m R N A, g R N A s, M O, D N A$, and protein}

Microinjections were performed using a PCI 100 Microinjector (Harvard Apparatus). Embryos at the 1-4 cell stage were injected with $2 \mathrm{nl}$ per embryo of appropriate concentration of mRNA, gRNA, MO, plasmid DNA, or protein. Cytoplasmic injections were performed for RNA injections while MOs and plasmid DNA were injected into the yolk-cytoplasm margin. The std MO was designed against the human $\beta$-globin intron that is not present in the zebrafish genome (Nasevicius and Ekker, 2000; Eisen and Smith, 2008; Bill et al., 2009; Moulton, 2017; Stainier et al., 2017).

Microinjection of cell surface markers $m G F P$ and mRFP. To achieve mosaic expression of the cell surface marker membrane-targeted green fluorescent protein (mGFP), plasmid (obtained from Richard Harland, University of California, Berkeley, CA) was prepared using a midiprep kit (Macherey-Nagel, catalog \#740410.10) and injected (50-200 pg) into $1-4$ cell stage embryos. Ubiquitous expression of the cell surface marker membrane-targeted red fluorescent protein (mRFP; plasmid provided by Steve Farber, Carnegie Institution for Science) (Megason and Fraser, 2003) was achieved by injecting mRNA encoding mRFP. Plasmid containing $m R F P$ was linearized with NotI, transcribed using SP6 mMESSAGE mMACHINE kit (Ambion, catalog \#AM1340) and injected (50 pg) at the 1-4 cell stage.

Microinjection of neoICD. Rescue experiments were performed by injecting 1-4 cell stage embryos with $5 \mathrm{ng}$ of neo 1 a MO2, $50 \mathrm{pg}$ of neoICD/ NeoICD ${ }^{m u t}$, or both.

All other microinjection experiments using nucleic acid or protein were performed as described in previous sections.

\section{Cell transplantation}

Transplantation was performed as described previously (Kemp et al., 2009; Jayachandran et al., 2010). Briefly, 50-100 cells from donors, injected with $m R F P$ RNA, were transplanted isochronically into the animal pole of host embryos at the sphere-dome stage injected with $m$ GFP DNA.

\section{Whole-mount in situ hybridization (WISH)}

Embryos were fixed in 4\% PFA at the desired stages and processed for in situ hybridization as previously described (Thisse and Thisse, 2008; Jayachandran et al., 2016), using riboprobes against zebrafish distal-less homeobox $3 B$ (dl $x 3 b$ ), rgma, and neola. Plasmid containing $d l x 3 b$ (obtained from Igor Dawid, National Institutes of Health) was linearized with NotI, and T7 polymerase was used to generate antisense probe. Sense and antisense riboprobes were synthesized from a pCRII-TOPO vector containing full-length zebrafish rgma (P.J. and R.B., unpublished) by linearizing/transcribing with NotI/SP6 and HindIII/T7, respectively. The neola EST $c b 333$ (Zebrafish Information Network) was linearized with ScaI, and T7 or T3 polymerases were used to generate sense and antisense riboprobes, respectively.

\section{Immunolabeling and staining}

For microtubule (MT) analysis, embryos were fixed in MT assembly buffer containing 3.7\% PFA, $0.25 \%$ glutaraldehyde, $0.2 \%$ Triton X-100, $1 \mathrm{~mm} \mathrm{MgCl}, 5 \mathrm{~mm}$ EGTA, and $0.5 \mu \mathrm{m}$ paclitaxel as previously described (Topczewski and Solnica-Krezel, 1999; Tran et al., 2012). For cell membrane analysis, embryos injected with $m G F P$ DNA or $m R F P$ mRNA were fixed in 4\% PFA and processed for immunofluorescence using 1:1000 rabbit anti-GFP antibodies (Invitrogen, catalog \#A11122; RRID: AB_221569). mRFP fluorescence was detected directly by confocal microscopy (described below). For analysis of F-actin, PFA (4\%)-fixed embryos were stained with 1:250 Phalloidin-Alexa-488 (Invitrogen, catalog \#A12379) for $2 \mathrm{~h}$ according to the manufacturer's protocol. Nuclei were labeled with DAPI (Invitrogen, catalog \#D1306) according to the manufacturer's instructions.

\section{Imaging embryos}

Bright field imaging. Live, dechorionated embryos were immobilized using the sedative tricaine methanesulfonate at $0.001 \% \mathrm{w} / \mathrm{v}$ in embryo medium E3 (5 mu NaCl, $0.33 \mathrm{~mm} \mathrm{CaCl}_{2}, 0.17 \mathrm{~mm} \mathrm{KCl}, 0.33 \mathrm{~mm} \mathrm{MgSO}_{4}$ ). Embryos were mounted on depression slides atop droplets of $4 \% \mathrm{w} / \mathrm{v}$ methylcellulose in E3. Side views of $32 \mathrm{hpf}$ larvae were captured at $50 \times$ total magnification on a Axioskop II compound microscope (Carl Zeiss) and AxioCam 503 CCD camera (Carl Zeiss).

For fixed preparations, embryos labeled using in situ hybridization were sectioned $(40 \mu \mathrm{m})$ at the level of the hindbrain using a sectioning system (Vibratome, 1500), mounted in glycerol, and imaged at 50× magnification using an AxioSkopII microscope (Carl Zeiss) and CCD camera (Q-Capture).

Confocal microscopy. Time-lapse microscopy was performed on dechorionated live embryos injected with fluorescent markers embedded in $<1 \mathrm{~mm}$ holes that were bored in $1.2 \%$ low melting point agarose (Shelton Scientific-IBI) solidified on glass-bottom culture dishes with size 1.5 coverslips (Mattek). Embryos were imaged from a dorsal view using an inverted SP5 laser scanning confocal microscope (Leica Microsystems) with a $40 \times$ oil objective lens.

For fixed preparations, immunolabeled embryos were sectioned (40 $\mu \mathrm{m}$ ) at the level of the hindbrain using a sectioning system (Vibratome, 1500 ) and mounted in $4 \%$ low melting point agarose for confocal imag- 
ing using an inverted confocal microscope (Leica Microsystems, SP5) with a $40 \times$ oil objective lens. Images were analyzed, processed, and annotated using ImageJ (National Institutes of Health), Photoshop (Adobe), and PowerPoint (Microsoft).

\section{Western blot analysis}

Embryos were mechanically lysed in precooled $1 \times$ RIPA buffer $(20 \mathrm{~mm}$ Tris-HCl, pH 7.5, $150 \mathrm{~mm} \mathrm{NaCl}, 1$ mm Na 2 EDTA, 1 mм EGTA, 1\% NP-40, 1\% sodium deoxycholate, $2.5 \mathrm{~mm}$ sodium pyrophosphate, $1 \mathrm{~mm}$ $\beta$-glycerophosphate, $1 \mathrm{~mm} \mathrm{Na} \mathrm{VO}_{4}$, and $1 \mu \mathrm{g} / \mathrm{ml}$ leupeptin) supplemented with protease inhibitors $(1 \times$ final concentration) (SigmaAldrich, catalog \#P8340). Bicinchoninic acid protein assay was used to determine the total protein concentration of embryonic lysates. Western blot analysis was performed by loading $7.5 \mu \mathrm{g}$ total protein per lane into 7.5\% Tris-glycine SDS-PAGE gels (Bio-Rad, catalog \#4561026) that were transferred to methanol-activated PVDF membranes. Specific protein detection was performed using diluted primary antibodies as follows: rabbit anti-Neo1 (LSBIO, catalog \#LS-B13131; RRID:AB_2620594) at 1:1000; custom-made rabbit anti-Rgma (GenScript; RRID:AB_2750931) at $0.64 \mathrm{ng} / \mathrm{ml}$; mouse anti-FLAG (GeneTex, catalog \#GTX18230; RRID:AB_423136) at 1:10,000; rabbit anti-GAPDH (GeneTex, catalog \#GTX124503; RRID:AB_11165273) at 1:1000-1:5000 and goat antirabbit secondary antibodies (Cell Signaling Technology, catalog \#7074; RRID:AB_2099233) at 1:10,000. Molecular weights were determined using prestained protein ladders (Thermo Fisher Scientific, catalog \#26616; GE Healthcare, catalog \#RPN800E). Protein abundance was detected using the SuperSignal West Femto enhanced chemiluminescence kit (Thermo Fisher Scientific, catalog \#34095) and Blu-C high-contrast autoradiography film (Stellar Scientific, catalog \#BLC-57-100).

\section{Drug treatments}

Inactivation of secretases. To inactivate secretases, embryos were pretreated with $1 \%$ DMSO in embryo medium (E3) at standard temperature $\left(28.5^{\circ} \mathrm{C}\right)$ for $1 \mathrm{~h}$ to permeabilize their chorions before treatment with inhibitors. The $\alpha$-secretase/a disintegrin and metalloprotease domain 17 (ADAM17) inhibitor, TNF $\alpha$ protease inhibitor I (TAPI-1) and the $\gamma$-secretase inhibitor $N$-[ $N$-(3, 5-difluorophenacetyl)-l-alanyl]-S-phenylglycine t-butyl ester (DAPT) were prepared freshly in prewarmed $1 \%$ $\mathrm{DMSO} / \mathrm{E} 3$ solution containing the proteasome and nuclear export inhibitors MG132 and leptomycin B (LMB), respectively, to suppress protein recycling and $0.002 \%$ methanol $(\mathrm{MeOH})$ to enhance drug solubility. Embryos were treated with $1 \%$ DMSO, $100 \mu \mathrm{M}$ TAPI-1, or $8 \mathrm{ng} / \mu \mathrm{l}$ DAPT starting and ending at the 6 somite and 20 somite stages (som), respectively, before mechanical lysis in $1 \times$ RIPA buffer.

Deglycosylation using PNGaseF. A $20 \mu$ l lysate of 1 d-post-fertilization (dpf) embryos was split evenly between two tubes (10 $\mu \mathrm{l}$ each) on ice. Lysates were treated with $5 \mu \mathrm{l}$ of PNGaseF buffer $(1 \times$ final concentration) with or without PNGaseF enzyme using a kit (NEB, catalog \#P0704). PNGaseF incubated on a thermocycler set at $37^{\circ} \mathrm{C}$ for $1 \mathrm{~h}$. Lysates were subjected to Western blotting under reducing conditions.

\section{Periodic acid Schiff assay}

Proteins obtained from 1 dpf std MO- or rgma MO2-injected larval lysates were concentrated using a 10,000 molecular weight (MW) protein concentrator column (Pierce, catalog \#88527) and separated using SDSPAGE on 7.5\% Tris-glycine polyacrylamide gels (Bio-Rad). Gels were processed for fuchsin labeling of periodic acid-oxidized glycans using the Glycoprotein Staining Kit (Thermo Fisher Scientific, catalog \#24562), according to the manufacturer's recommendations. Replicate lanes were stained with Coomassie to assay total protein or transferred to PVDF membranes for Western blot analysis using Neol antibodies.

\section{Subcellular fractionation}

The $1 \mathrm{dpf}$ larvae were mechanically lysed in precooled $\left(4^{\circ} \mathrm{C}\right) 1 \times \mathrm{RIPA}$ buffer (20 mu Tris-HCl, pH 7.5, $150 \mathrm{~mm} \mathrm{NaCl}, 1$ mм Na 2 EDTA, 1 mm EGTA, $1 \%$ NP-40, $1 \%$ sodium deoxycholate, $2.5 \mathrm{~mm}$ sodium pyrophosphate, $1 \mathrm{~mm} \beta$-glycerophosphate, $1 \mathrm{~mm} \mathrm{Na}_{3} \mathrm{VO}_{4}$, and $1 \mu \mathrm{g} / \mathrm{ml}$ leupeptin) supplemented with protease inhibitors $(1 \times$ final concentration). Lysates were centrifuged at 6000 revolutions per minute at $4^{\circ} \mathrm{C}$ for 6 min to pellet nuclei. Supernatants were transferred to fresh tubes and stored on ice. Pellets were washed twice in precooled $\left(4^{\circ} \mathrm{C}\right) 1 \times$ RIPA with protease inhibitors and stored on ice; $6 \times$ reducing sample buffer $(375 \mathrm{~mm}$ Tris$\mathrm{HCl}, \mathrm{pH} 6.8,6 \%$ SDS, $9 \% \beta$-mercaptoethanol, $0.03 \%$ bromophenol blue, $4.8 \%$ glycerol) was added to nuclear pellets and supernatants at a final concentration of $1 \times$ before boiling sample for Western blot analysis.

\section{Measurements}

All measurements of neural tissue were taken at the level of the hindbrain that was identified with several visual landmarks (shape of neural keel or NT, presence of otic vesicles).

NP width. NP width was measured as the distance (in micrometers) between the lateral domains of $d l x 3 b$ expression at the level of rhombomere 5 , as confirmed by krox20 labeling.

NEC length-to-width ratio. The NEC length-to-width ratio was obtained by measuring the long and short axes (in micrometers) of mGFPor mRFP-expressing NECs in hindbrain sections of embryos at 4-5 som.

$C$ division index, distribution, and orientation. Measurements were taken from single-frame images of $8-10$ som embryos labeled with anti$\beta$-tubulin, counterstained with DAPI, and sectioned at the level of the hindbrain. ImageJ (National Institutes of Health) was used to quantify mitotic indices, the position of $\mathrm{C}$ divisions relative to the midline, and the angle of $\mathrm{C}$ divisions relative to the midline. Mitotic indices were quantified in the medial aspect of the neural tissue (region spanning $30 \mu \mathrm{m}$ on either side of the midline) as the number of nuclei with condensed chromatin divided by the total number of nuclei multiplied by 100 . To determine the angle of cell divisions, a line (radial distance, $r$ ) was drawn to connect the condensed chromatin of conjoined daughter cells at the telophase stage. The orientation of $\mathrm{C}$ divisions was scored as the elevation angle or azimuthal angle $(\theta)$ between $r$ and the mediolateral (horizontal) axis of the neural tissue, such that a mediolaterally oriented $\mathrm{C}$ division has a value of $0^{\circ}$. For metaphase cells, $r$ was inferred from the orientation of mitotic spindles stained by $\beta$-tubulin antibodies.

\section{Experimental design and statistical analyses}

Graphing and statistical analyses were performed using Prism 7 (GraphPad). Statistical significance was declared in circumstances where $p \leq$ 0.05 . Experiments comparing three or more groups were analyzed by one-way ANOVA. When comparing 2 means within a dataset, $p$ values were obtained by performing a post hoc Tukey test. Data were reported as the mean \pm SEM unless otherwise indicated.

\section{Rose plots (radial grids)}

Image stacks from time-lapse microscopy were collapsed to a single frame for each time point using Volocity version 5.5 (PerkinElmer) and exported as Tif files. Only interphase cells that remained in-frame for the duration of the movie were analyzed. Using a plugin created for ImageJ (National Institutes of Health), individual cells were thresholded and outlined. Based on the centroid and the orientation relative to the midline, each cell was then divided into 8 radial segments. Finally, individual frames were superimposed, and any new membrane extensions of 3 pixels or more were counted for each segment and frame. The percentage of protrusions for each segment was then quantified and graphed in Mathematica version 9 (Wolfram).

\section{Results}

\section{Tools for knocking down Rgma and Neo1}

In contrast to other vertebrate models used to study neurulation, zebrafish undergo delayed establishment and maturation of apicobasal polarity, and hinge points have not been reported in this organism (Geldmacher-Voss et al., 2003; Lowery and Sive, 2004; Hong and Brewster, 2006), enabling the identification of molecular pathways controlling NEC elongation independently of those required for epithelialization. To address whether activation of Neol signaling is an early event that controls NEC elongation, we generated and validated several loss-of-function (LOF) tools for functional characterization of both Rgma and its receptor, Neol. 
A
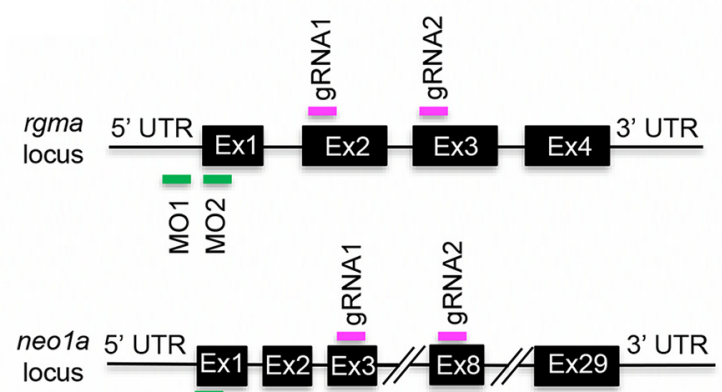

locus

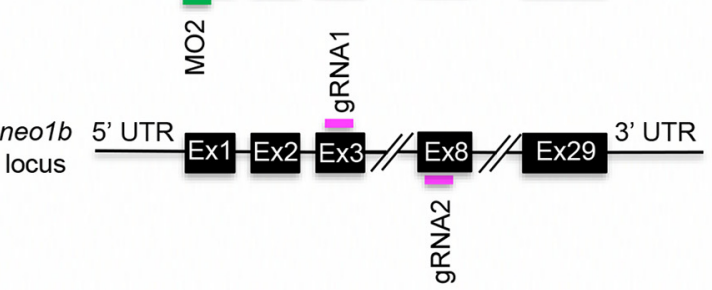

H

neola MO2 1> -GGCUCCCCGCUCCGCCAUCACUUUA $>25$ neola mRNA 25> -GGCUCCCCGCUCCGCCAUCACUUUA $<1$ neo1b mRNA 25> UUGCU-CCCGCUCCGCCAUCACUUUC $<1$

I

\begin{tabular}{|c|c|c|c|c|}
\hline \multicolumn{5}{|c|}{ Neo1a } \\
\hline$s$ & $\lg x 4$ & FNIII x6 & $\mathrm{TM}$ & $\mathrm{ICD}$ \\
\hline 1 & \multicolumn{2}{|c|}{ Neo1a ${ }^{\delta 1133-F L A G}$} & \multicolumn{2}{|c|}{1132} \\
\hline$s$ & $\lg x 4$ & FNIII $\times 6$ & TM & \\
\hline
\end{tabular}

J

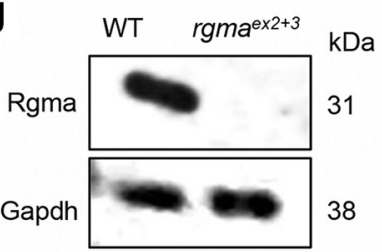

$\mathbf{L}$

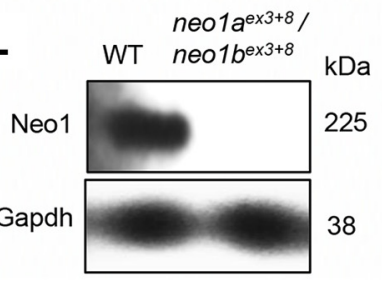

$\mathbf{K}$

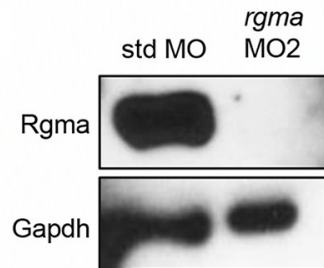

M

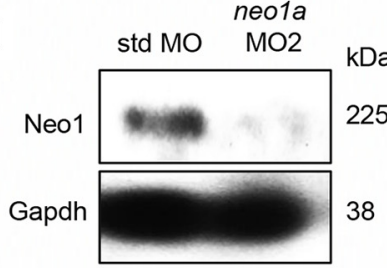

38

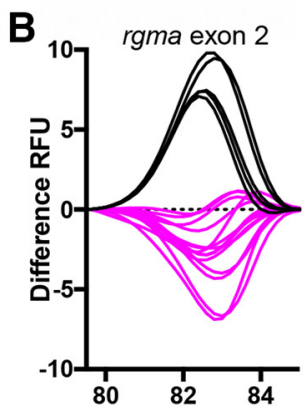

D

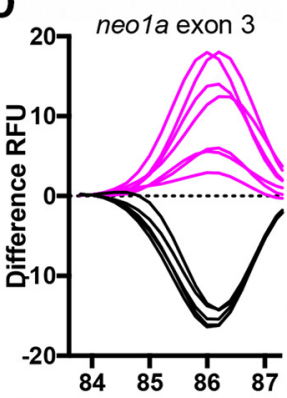

E
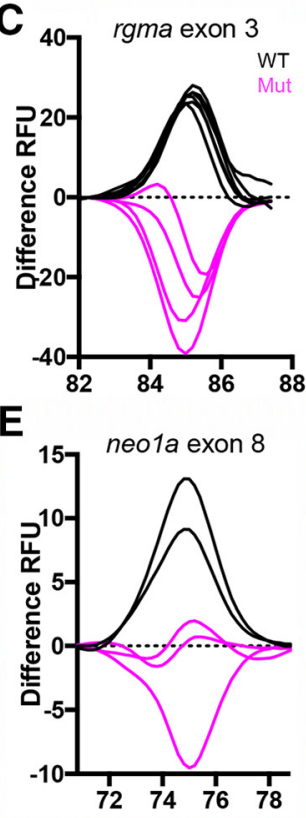

F

$\left.\mathbf{G}_{40}\right]^{\text {neo } 1 b}$ exon 8
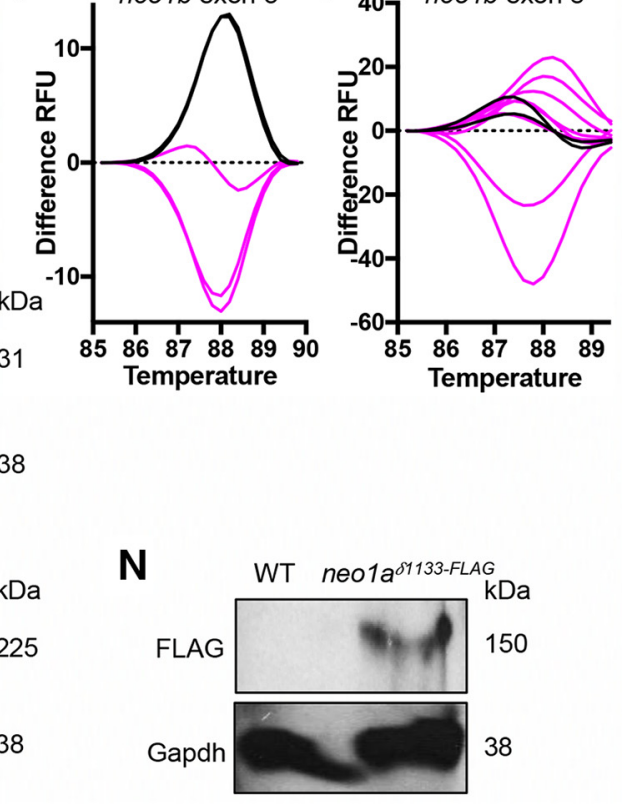

Figure 1. Rgma and Ne01 LOF tools. A, Schematic representation of rgma, neo $1 a$ and neo1b loci showing exons (Ex, black boxes) and $5^{\prime}$ and $3^{\prime}$ untranslated regions of the genes (5'UTR and $3^{\prime}$ UTR) and target sites for MOs (green bars) and gRNAs (magenta bars). $\boldsymbol{B}-\mathbf{G}$, High-resolution melt analysis of indels in embryos co-injected with HF-nCas 9 and gRNAs against rgma exons 2 ( $\boldsymbol{B}$ ) and $3(\boldsymbol{C}$, neo 1a exons $3(\boldsymbol{D})$ and $8(\boldsymbol{E})$, and neo $1 b$ exons $3(\boldsymbol{F})$ and $8(\boldsymbol{G})$. Each line indicates relative fluorescence units (RFUs) over a range of temperatures corresponding to individual uninjected (control) $24 \mathrm{~h}$ post-fertilization (hpf) embryos (black graph lines) or Cas9/gRNA-coinjected embryos that accumulate mosaic indels in somatic and germ line cells (magenta graph lines). $\boldsymbol{H}$, Alignment of the neo $1 a \mathrm{M} 02$ target sequence to the neo $1 a$ and neo $1 b$ transcripts. The underlined residues indicate the translational start site. The nucleotides in bold are not conserved. $I$, Schematic of Neo1a (top) and predicted protein product of neo $1 a^{\delta 1133} \mathrm{mRNA}$ lacking the NeoICD (bottom). S, Signal peptide; IgG, immunoglobulin domain; FN, fibronectin domain; TM, transmembrane domain.J, $K$, Western blot analysis of Rgma protein levels in embryos injected with multiplexed rgma gRNAs with Cas $9(\boldsymbol{J})$ and $M 02(\boldsymbol{K})$, compared with uninjected controls and std $M 0$-injected embryos, respectively. $\boldsymbol{L}$, $\boldsymbol{M}$, Western blot analysis of Ne01 protein levels in embryos injected with multiplexed neo1a and neo1b gRNAs with Cas9 $(\boldsymbol{L})$ and neo1a M02 (L), compared with uninjected controls and std M0-injected embryos, respectively. $N$, Detection of the FLAG epitope by Western blot in control (uninjected) and neo $1 a^{\delta 1133-F L A G} \mathrm{mRNA}$-injected embryos. Each lane was loaded with $5 \mu \mathrm{g}$ of total protein with Gapdh used as a loading control $(\boldsymbol{J}-\boldsymbol{N})$.

Whereas rgma is encoded by a single gene in the zebrafish genome (accession \#Q58EQ5), there are two neol paralogs, neola (accession \#NM_173218) and neolb (accession \#E7F004), mapping to chromosomes 7 and 2, respectively. These paralogs share $65 \%$ overall amino acid homology and $99 \%$ homology in their $\mathrm{C}$-terminal regions and may therefore be functionally redundant. LOF tools that target both neol paralogs in addition to rgma were therefore generated (Fig. 1), which include the following: CRISPR/Cas9-induced indels in the rgma (Fig. 1A-C,J), neola (Fig. $1 A, D, E, L$ ), and neolb (Fig. $1 A, F, G, L$ ) loci using two gRNAs per gene, translation-blocking MOs (rgma MO1 and MO2) that target the 5'UTR (Fig. 1A, top) and the translational start site region (AUG) of rgma, respectively (Fig. $1 A, K$ ) as well as the neola AUG (neola MO2) (Fig. 1A,M) and a neola construct 
predicted to function in a dominant-negative manner to disrupt Rgma-Neo downstream signaling, neo $1 a^{\delta 1133-F L A G}$, which encodes a truncated protein lacking terminal amino acids 11331428 (Fig. 1I,N) (Wilson and Key, 2006).

rgma maternal-zygotic homozygous mutant lines generated using CRISPR/Cas9 genome editing (gRNAs targeting rgma exon 2 exclusively) appeared phenotypically WT (data not shown), a likely consequence of compensatory mechanisms that have been frequently reported, including upregulation of paralogs (Hartman et al., 2001; Gu et al., 2003; Conant and Wagner, 2004; Hanada et al., 2011; Sztal et al., 2018; To and Andrechek, 2018), nonhomologous genes (Peng et al., 2012; Li et al., 2014), and exon-skipping (Oda et al., 2016; Anderson et al., 2017; Moulton, 2017; Sharpe and Cooper, 2017). However, high-resolution melt analysis revealed that gRNAs targeting rgma exons 2 or 3 generated indels at high frequency (Fig. $1 B, C$ ), and the combined use of these gRNAs depleted Rgma protein in the first generation of injected embryos (F0s) (Fig. 1J). Likewise, we observed indels in embryos injected with Cas9 protein and gRNAs targeting neola exons 3 and 8 (Fig. $1 D, E$ ) or neolb exons 3 and 8 (Fig. $1 F, G$ ) and a corresponding depletion of Neo1 protein levels in embryos injected with gRNAs targeting all 4 exons (Fig. $1 L$ ).

Western blot analysis further revealed that the MOs targeting rgma and neo1 were effective. rgma MO2 fully depleted Rgma protein $($ Fig. $1 K$ ). Using anti-Neo1, which is predicted to recognize the $\mathrm{C}$ terminus of both Neola and Neolb, we observed that Neo1 was substantially, but not fully, depleted in neola MO2injected embryos (Fig. 1M). This partial depletion suggests that neola $\mathrm{MO}$ targets the neo la paralog only, which is consistent with the mismatched residues between the ATG region of neo $1 b$ and the neo1a MO2 sequence (Fig. $1 H$ ).

Last, we observed a $150 \mathrm{kD}$ band in Western blots of protein extract from neo $1 a^{\delta 1133-F L A G}$-injected embryos using anti-FLAG, which corresponds to the truncated, FLAG-tagged protein. This band was not observed in control, uninjected embryos (Fig. 1I,N).

\section{Morphological defects associated with Rgma and Neo1 LOF}

To evaluate the efficacy of these LOF tools, embryos injected with rgma MO 1 or 2, neo1 MO2, neo1a $a^{\delta 1133-F L A G}$, or Cas9/gRNAs targeting rgma $\left(\right.$ rgma $\left.^{\text {ex2 }+3}\right)$, neola $\left(\right.$ neol $\left.a^{\text {ex3 }}+8\right)$, neolb $\left(\right.$ neol $\left.a^{\text {ex3 }+8}\right)$, or neola and neolb (neol $a^{\text {ex3+8}} /$ neo $1 b^{\text {ex3+8}}$ ) were examined at 32 hpf for morphological defects (Fig. 2). In contrast to control embryos (uninjected and standard std MO-injected), perturbation of Rgma or Neo1 function caused graded phenotypes ranging from WT to severe (Fig. 2A-I). Phenotypes observed consisted of a shortened anterior-posterior axis, absence of brain morphological landmarks (forebrain, hindbrain, midbrainhindbrain boundary), abnormally shaped somites, small eyes, and pigmentation. The mild, moderate, and severe phenotypic categories displayed one, two or three, or at least four of these traits, respectively (Fig. $2 J$ ). These observations indicate that rgma and neola/b are required to shape the early embryo, consistent with their maternal expression and distribution at later stages in neural tissue, mesoderm, and retina primordia (Thisse et al., 2001; Shen et al., 2002). Since neo1a and neo1b depletion causes severe morphological defects, they are at most partially redundant. Overall, these data support the model that Rgma and Neo1 function as a ligand-receptor pair during early development. Given the similarity between these phenotypes, we have used neo1a $\mathrm{MO} 2$ and rgma MO2 to perform some of the functional studies described below.

\section{Rgma-Neo1a signaling promotes NEC elongation}

To test the requirement of Rgma-Neol signaling in NEC elongation, we analyzed cell shapes in embryos co-injected with $m G F P$ plasmid (for mosaic expression) and one of the following neola or rgma LOF tools: neola MO2, rgma MO2, neola gRNA exon $3+8$ and HF-nCas9 or rgma gRNA exons $2+3$ and and HFnCas9, as previously described (Jayachandran et al., 2010) (Fig. $3)$. We observed that Neola- and Rgma-depleted NECs appeared rounder (Fig. $3 B, B^{\prime}, D, D^{\prime}, C, C^{\prime}, E, E^{\prime}$, respectively) than uninjected control cells (Fig. $3 A, A^{\prime}$ ), consistent with impaired cell elongation. Measurement of length-to-width ratios (LWRs) confirmed a significant difference in cell shape between control cells and experimental groups $\left(F_{(4,740)}=67.48, p<0.0001\right.$, ANOVA $)$ (Fig. $3 F)$. Whereas the mean LWR for control cells was $3.58 \pm$ 0.14 ( $n=55$ cells, 5 embryos, $p<0.0001$, Tukey test), the LWRs of neola MO2 and neo1 a gRA exon $3+8$ injected embryos was $1.54 \pm 0.04(n=121$ cells, 5 embryos, $p<0.0001$, Tukey test $)$ and $2.238 \pm 0.07$ ( $n=188$ cells, 10 embryos, $p<0.0001$, Tukey test $)$, respectively, whereas the LWR of rgma $\mathrm{MO} 2$ and $\mathrm{rgma}$ gRNA exon $2+3$ injected embryos was $1.55 \pm 0.04(n=90$ cells, 5 embryos, $p<0.0001$, Tukey test) and $2.034 \pm 0.05$ ( $n=291$ cells, 10 embryos, $p<0.0001$, Tukey test), respectively. To gain a better understanding of the dynamic cell shape changes that take place during infolding and the role of Neola signaling in this process, we performed time-lapse imaging of control and Neola-depleted embryos that mosaically express mRFP (Fig. 3G,H; Movies 1, 2). These movies, spanning 1-2 som to 5-6 som, revealed that control cells were initially rounded but gradually elongated along their prospective apico-basal polarity axis (Fig. $3 G ; n=6$ cells from 3 embryos). In contrast, NECs in neola MO2-injected embryos remained rounded throughout the duration of time-lapse imaging ( $87 \mathrm{~min}$ ) (Fig. $3 H ; n=6$ cells from 3 embryos). To further analyze these cell behaviors, the outlines of interphase cells were traced, revealing a striking defect in cell elongation in Neola-depleted NECs compared with control cells (Fig. 3I and Fig. 3J, respectively). Furthermore, graphical representation of the distribution of the cell surface using rose plots confirmed that Neola-depleted NECs (Fig. $3 L$ ) failed to redistribute their plasma membrane along the mediolateral axis during infolding in contrast to control cells (Fig. $3 K)(n=6$ cells/embryo; $n=3$ embryos). All the cells analyzed displayed a similar behavior. Together, these data are consistent with the proposed role of RgmaNeola signaling in promoting cell elongation during infolding.

\section{rgma and neo1 $a$ are expressed in the developing NT}

If rgma and neola directly control NEC elongation, both genes (or at least the receptor, neola) should be expressed in the developing NT. To test this, we analyzed their mRNA distribution in the presumptive hindbrain, at the NP (tailbud), neural keel (4-5 som), and neural rod ( $8-10$ som) stages using WISH (Fig. 4). At the NP stage, cells in the deep neural layer express neola, consistent with the expression reported for its orthologue Xneog in Xenopus (Kee et al., 2008), and no labeling was detected in the superficial neural layer (Fig. 4A). neo $1 a$ expression was also observed in the lateral plate mesoderm at this and later stages (Fig. $4 A-C$ ). The spatial distribution of neola expands in older embryos, as weak expression is observed in the deep and superficial layers of the neural keel (Fig. $4 B$ ) and becomes more intense in the dorsal region of the neural rod (Fig. 4C). neo $1 b$ was expressed uniformly across the neural keel (data not shown), overlapping with the neola expression domain. 

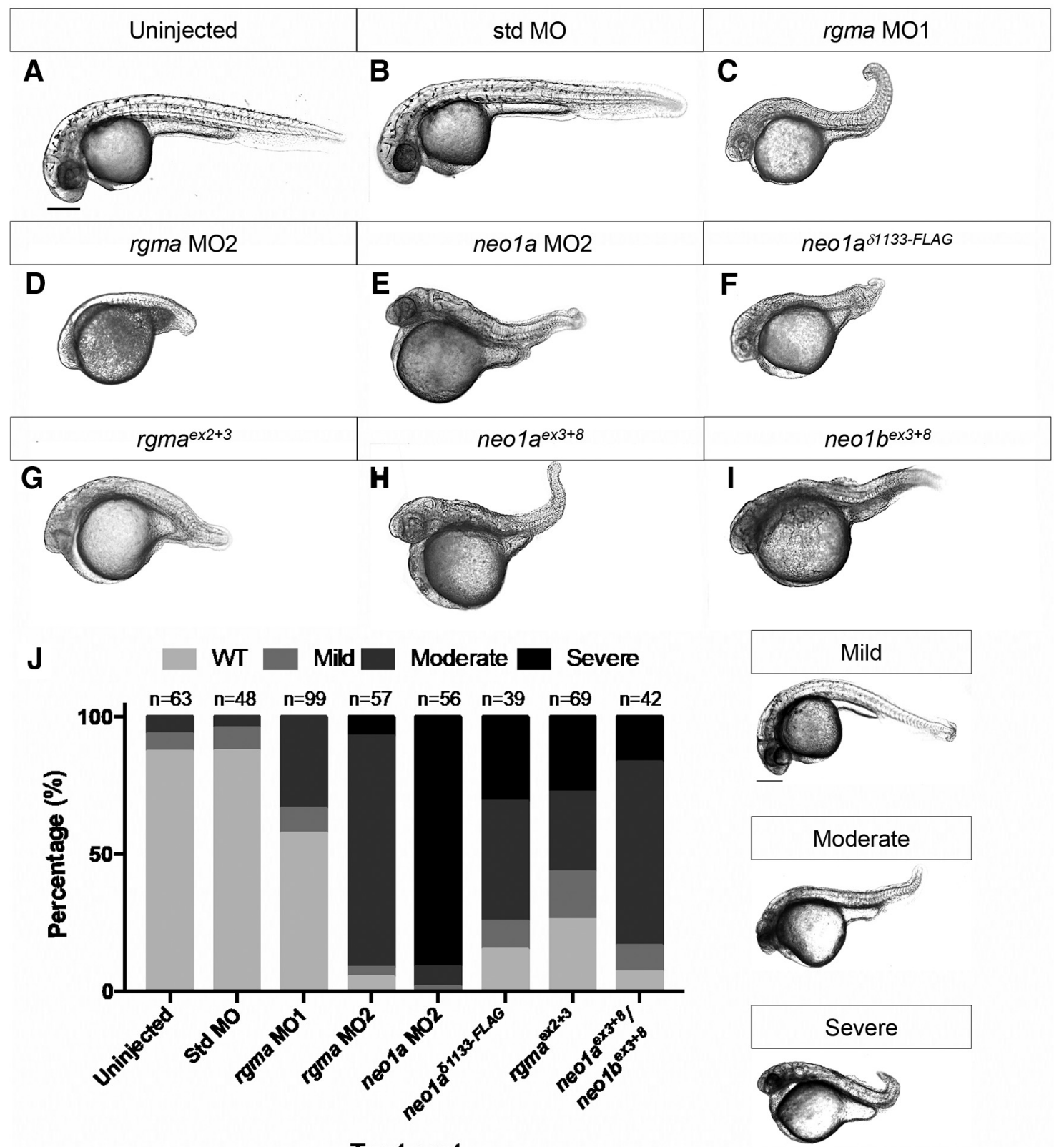

Treatment

Figure 2. Morphological defects observed in Rgma and Ne01 LOF embryos. $A-I$, Bright field images of $32 \mathrm{hpf} \mathrm{larvae} \mathrm{that} \mathrm{were} \mathrm{uninjected}(\boldsymbol{A})$ or injected with the following molecular tools: std

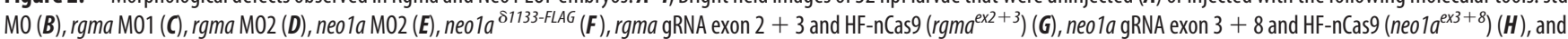
neo $1 b$ gRNA exon $3+8$ and HF-nCas9 $\left(\right.$ neo $\left.1 b^{\text {ex3 } 3+8}\right)(\boldsymbol{I})$. Scale bar, $250 \mu \mathrm{m}$.J, Distribution of WT and LOF phenotypes in $32 \mathrm{hpf}$ embryos treated as in $A-I$, with the exception of the last dataset (far right column) showing phenotypic distribution for multiplexed neo $1 a^{\text {ex }}{ }^{3+8}$ and neo $1 b^{\text {ex3+8}}$. WT, mild, moderate, and severe phenotypes exhibited $0,1,2-3$, and 4 or more of the following features, respectively: a shortened anterior-posterior axis, poorly defined brain morphological landmarks, misshaped somites, small eyes, and decreased pigmentation (the latter is indicative of developmental delay). Uninjected: $\mathrm{WT}=87 \%$, mild $=6 \%$, moderate $=6 \%$, severe $=0 \%, n=63 ;$ std M0: WT $=88 \%$, mild $=8 \%$, moderate $=4 \%$, severe $=0 \%, n=48 ;$ rgma $\mathrm{M} 01: \mathrm{WT}=$ 58 , ild $=9 \%$, moderate $=33 \%$, severe $=0 \%, n=99 ;$ rgma MO2: WT $=5 \%$, mild $=4 \%$, moderate $=84 \%$, severe $=7 \%, n=57 ;$ neo $1 a \mathrm{MO2}:$ WT $=0 \%$, mild $=2 \%$, moderate $=7 \%$, severe $=91 \%, n=56 ; n$ neo $1 a^{81133-\text { LLAG }}:$ WT $=15 \%$, mild $=10 \%$, moderate $=44 \%$, severe $=31 \%, n=39 ;$ rgma ${ }^{\text {ex } 2+3}:$ WT $=26 \%$, mild $=17 \%$, moderate $=29 \%$, severe $=28 \%, n=69$; neo $1 a^{e \times 3+8} /$ neo $1 b^{e \times 3+8}: \mathrm{WT}=7 \%$, mild $=10 \%$, moderate $=67 \%$, severe $=17 \%, n=42$. Data represent pooled results from 3 independent experiments.

At the NP (Fig. 4G), neural keel (Fig. $4 H$ ), and neural rod stages (Fig. 4I), rgma is strongly expressed in the notochord and floor plate and to a lesser extent in the overlying neural tissue, where it is restricted to the ventral region of the neural keel and rod (Fig. 4H,I). This distribution is consistent with that of Xenopus Xrgma, which is robustly expressed in the deep and medial cells of NP and ventral NT, although no expression was detected in the notochord (Kee et al., 2008). The specificity of the labeling was confirmed using sense riboprobes for neola (Fig. $4 D-F$ ) and rgma (Fig. 4J-L). Thus, rgma and neola are expressed in a spatial and temporal manner that is consistent with their proposed function in regulating NEC elongation. However, the strong expression of both genes in the mesoderm raises the question of whether the NEC elongation defect we observe in Neola-depleted embryos may be indirectly attributed to defective convergent extension movements in the mesoderm (Mawdsley et al., 2004), especially given the severe anteroposterior axis shortening we observed in Neola knockdown embryos (Fig. 2E, F,H). 

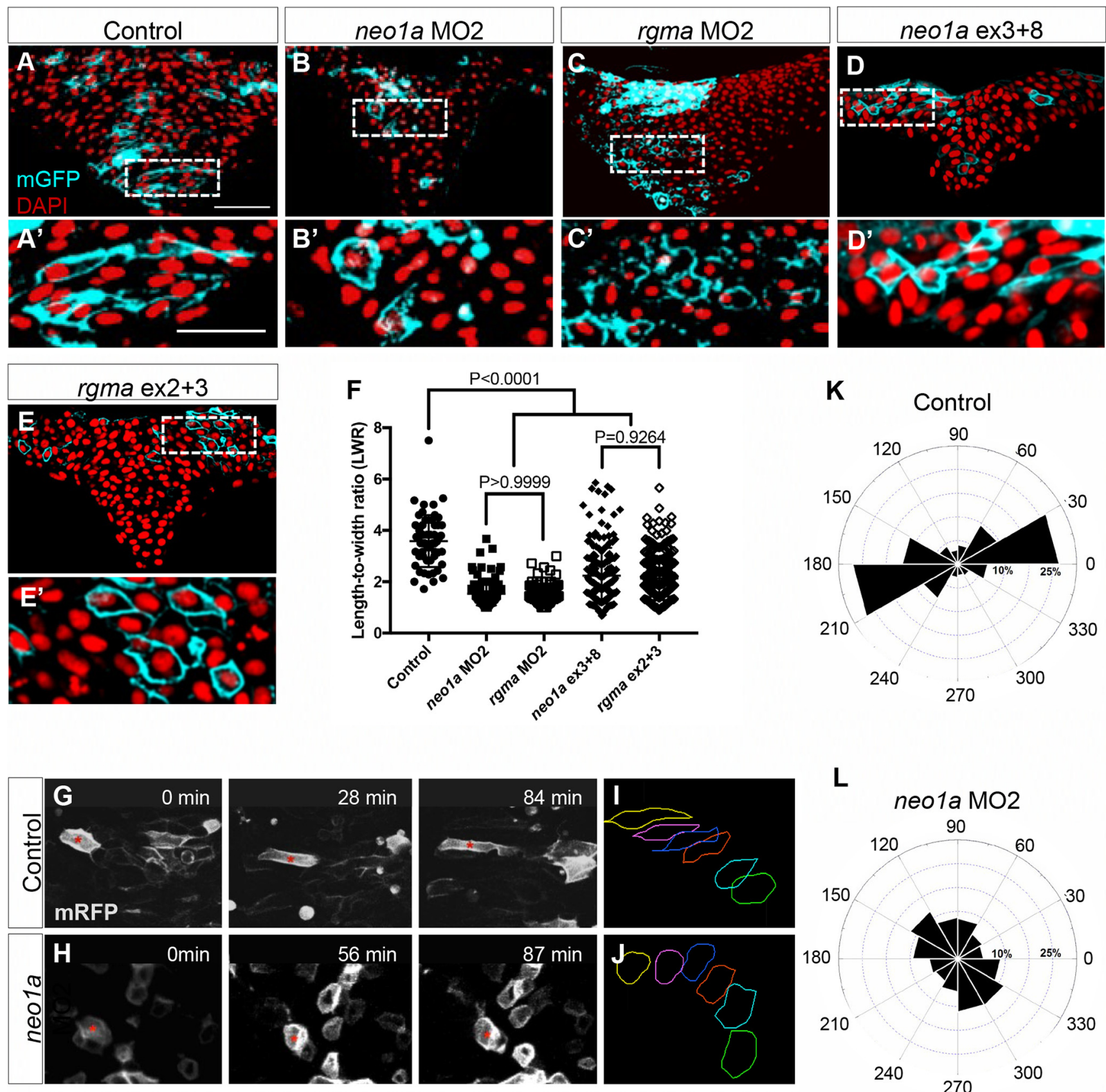

Figure 3. Rgma and Neo1a are required for NEC elongation during infolding. $\boldsymbol{A}-\boldsymbol{E}$, Mosaic $\mathrm{mGFP}$ signal (cyan) was detected by immunofluorescence using anti-GFP antibodies along with DAPI counterstain of nuclei (red) on hindbrain transverse sections of $4-5$ som embryos that were uninjected $(\boldsymbol{A})$, injected with neo $1 a \mathrm{MO} 02$ (B), rgma M02 (C), neo $1 \mathrm{a} / \mathrm{b}$ gRNA exon $3+8$ and HF-nCas9 (D), or rgma gRNA exon $2+3$ and HF-nCas9 (E). Scale bar, $50 \mu \mathrm{m}$. $\boldsymbol{A}^{\prime}-\boldsymbol{E}^{\prime}$, Insets, Higher magnification of NEC morphology within the selected regions in $\boldsymbol{A}-\boldsymbol{E}$. Scale bar, $50 \mu \mathrm{m}$. $\boldsymbol{F}$, Quantification of $L W R s$ of labeled NECs in 5-10 embryos from each group treated as in $\boldsymbol{A}-\boldsymbol{E}$. $\mathbf{G}, \boldsymbol{H}$, Selected frames from time-lapse imaging of live NECs in control (top) and neo $1 a$ M02-injected (bottom) embryos mosaically labeled with $m R F P$ DNA and imaged in the hindbrain region from a dorsal view, beginning at $\sim 1-2$ som and extending through $5-6$ som. $I, J$, Representative traces of individual labeled cells from control $(\boldsymbol{G})$ and neo $1 a \mathrm{MO}$-injected $(\boldsymbol{H})$ embryos as in $\boldsymbol{G}$ and $\boldsymbol{H}$. Colored traces represent changes in shape and position of individual NECs over time. Green trace represents time 0 . Yellow trace represents last time point. Red dotted line indicates midline. $\boldsymbol{K}, \boldsymbol{L}$, The $30^{\circ}$ radial grid (rose plot) showing the average cell shape change over time of control, uninjected, and Neo1a-depleted $\mathrm{NECS}$, where $0^{\circ}$ and $180^{\circ}$ are medial and lateral extremes along the mediolateral axis of the neural keel, respectively.

Neola functions cell autonomously in the neuroectoderm To address whether Neola signaling is specifically required within the neural ectoderm to drive NEC elongation, we used cell transplantation to generate chimeric embryos consisting of WT and Neo1-depleted cells and measured NEC LWRs in transverse sections at the level of the hindbrain $\left(F_{(3,349)}=85.9, p<0.0001\right.$, ANOVA). mRFP and mGFP were used to differentially label cells from the donor and host, respectively. Donor embryos were injected at the 1 cell stage with mRNA encoding mRFP to uniformly label all cells. Hosts (recipients) were injected with DNA encoding mGFP, to mosaically express this reporter throughout the embryo (Fig. $5 A-C^{\prime}$ ). When control (mRFP and Neolaexpressing) cells were transplanted into host embryos, both donor and host NECs exhibited a comparable mean LWR (LWR of control donor cells $=3.54 \pm 0.10 ; n=100$ cells from 18 embryos, LWR of control host cells $=3.70 \pm 0.17 ; n=67$ cells from 14 embryos; $p=0.7348$, Tukey test; Fig. $5 D$ ), which is consistent with previous measurements from uninjected embryos (Fig. $3 F$ ). 


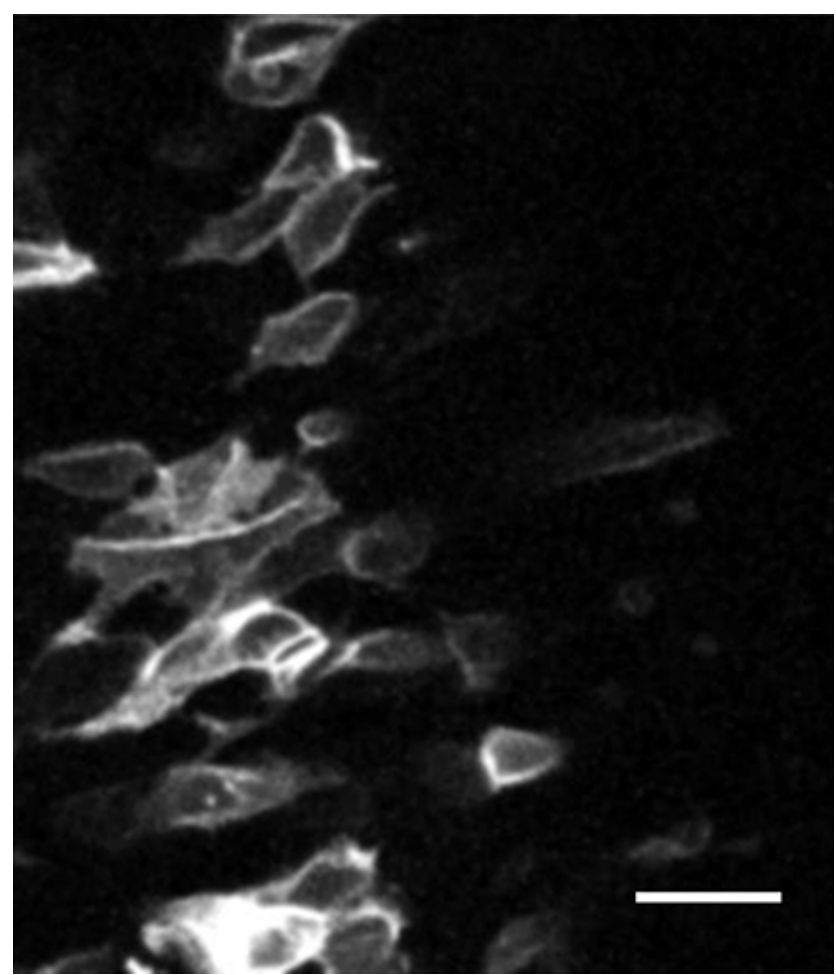

Movie 1. Time-lapse imaging of cell behaviors during infolding in a WT embryo. Time-lapse movie (1 min intervals) of a control, mRFPlabeled embryo that was imaged from a dorsal view, anterior toward the top, beginning at $\sim 2-3$ som and extending to $4-5$ som. Scale bar $50 \mu \mathrm{m}$.

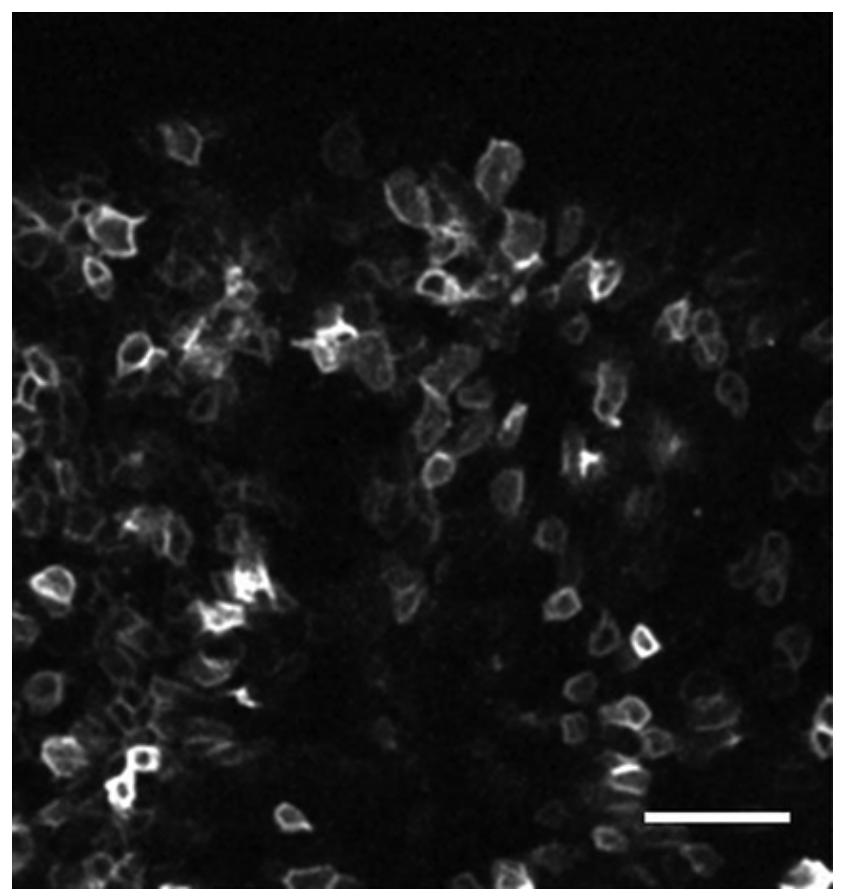

Movie 2. Time-lapse imaging of cell behaviors during infolding in Neo1a-depleted embryos. Time-lapse movie (1 min intervals) of a neo1a M02-injected, mRFP-labeled embryo that was imaged from a dorsal view, anterior toward the top, beginning at $\sim 2-3$ som and extending to $4-5$ som. Scale bar, $20 \mu \mathrm{m}$.
However, when Neo1-depleted cells (from embryos injected with $m R F P$ and neo1a MO2) were transplanted into host embryos, donor cells displayed lower LWRs compared with their neighboring host cells (LWR of host cells $=3.18 \pm 0.10 ; n=94$ cells from 9 embryos, LWR of Neola-depleted cells $=1.54 \pm 0.04 ; n=92$ cells from 10 embryos; $p<0.0001$, Tukey test; Fig. 5D). Even though the reciprocal experiment, transplanting control (Neolaexpressing) cells into neo1a MO2-injected hosts failed due to embryonic lethality, our transplantation data indicate that Neola functions in a cell-autonomous manner to regulate cell elongation in the neuroectoderm.

\section{Rgma and Neola depletion impairs infolding}

NEC elongation is a prerequisite for radial intercalation and establishment of transient contacts between contralateral NECs, cell behaviors that promote infolding of the NP (Papan and Campos-Ortega, 1994; Davidson and Keller, 1999; Marsden and DeSimone, 2001; Hong and Brewster, 2006). To test whether Rgma-Neola signaling is required for infolding, we compared the width of the NP in embryos injected with neola MO2 or rgma $\mathrm{MO} 2$ with that of control embryos that were either uninjected or injected with std $\mathrm{MO}\left(F_{(7,181)}=35.47, p<0.0001\right.$, ANOVA $)$. The $4-5$ som embryos were processed for WISH using either $d l x 3 b$ or krox 20 to image and measure the width of the NP at the level of rhombomere 5, which coincides with the position of the otic placode (Fig. 6A, B). We observed that the NP widths of embryos injected with rgma MO1 (248.4 $\pm 16.66 \mu \mathrm{m}, n=12$ embryos, $p=0.0356$, Tukey test), rgma MO2 (351.8 $\pm 9.254 \mu \mathrm{m}, n=18$ embryos, $p<0.0001$, Tukey test), neo1a MO2 (358.1 \pm 12.22 $\mu \mathrm{m}, n=7$ embryos, $p<0.0001$, Tukey test), neo1a ${ }^{\delta 1133-F L A G}$ (340.0 $\pm 18.53 \mu \mathrm{m}, n=39$ embryos, $p<0.0001$, Tukey test), rgma $^{\text {ex } 2+3}:(207.9, n=22$ embryos, $p<0.0001$, Tukey test $)$, and neo $1 a^{\text {ex3+8}} /$ neo $1 b^{\text {ex } 3+8}(213.3 \pm 21.51 \mu \mathrm{m}, n=22$ embryos, $p=$ 0.0272 , Tukey test) were significantly wider than those of uninjected (148.0 $\pm 1.413 \mu \mathrm{m}, n=60$ embryos), and std MO-injected (145 $\pm 3.641 \mu \mathrm{m}, n=9$ embryos, Fig. $6 C$ ). Together, these findings suggest that Rgma and Neola mediate NP infolding by regulating NEC elongation.

\section{Rgma and Neo1 a depletion causes duplication of the NT}

In the zebrafish neural rod, daughter cells of NECs integrate into opposite sides of the NT, a mode of cell division known as midline-crossing division ( $\mathrm{C}$ division). This mode of division is a mechanism used in this organism to establish apico-basal polarity, as the polarity protein Pard3 localizes to the cleavage furrow of mitotic progenitors cells and is mirror-symmetrically inherited by both daughter cells, marking their apical pole (which coincides with the apical midline of the NT) (Tawk et al., 2007). When convergence and/or infolding is delayed in planar cell polarity mutants, $\mathrm{C}$ divisions occur away from the midline of the widened neural tissue (neural rod stage), preventing midlinecrossing and resulting in a duplication of the apical midline of the NT (Tawk et al., 2007; Clarke, 2009).

To test whether the widened neural keel in embryos with impaired Rgma-Neo1 signaling alters the frequency, distribution, or orientation of C divisions, we labeled 8-10 som embryos with the nuclear marker DAPI and anti- $\beta$-tubulin and examined mitotic progenitors in rgma MO2-injected embryos and uninjected controls, at the level of the hindbrain (Fig. $7 A, B$ ). We observed that Rgma knockdown did not significantly impact the mitotic index in the neural rod (control mean mitotic index: uninjected controls: $5.21 \pm 0.99 \%, n=4$ embryos; rgma MO2-injected embryos: $2.91 \pm 0.63 \%, n=6$ embryos, $p=0.0740, t=2.054$, $\mathrm{df}=$ 


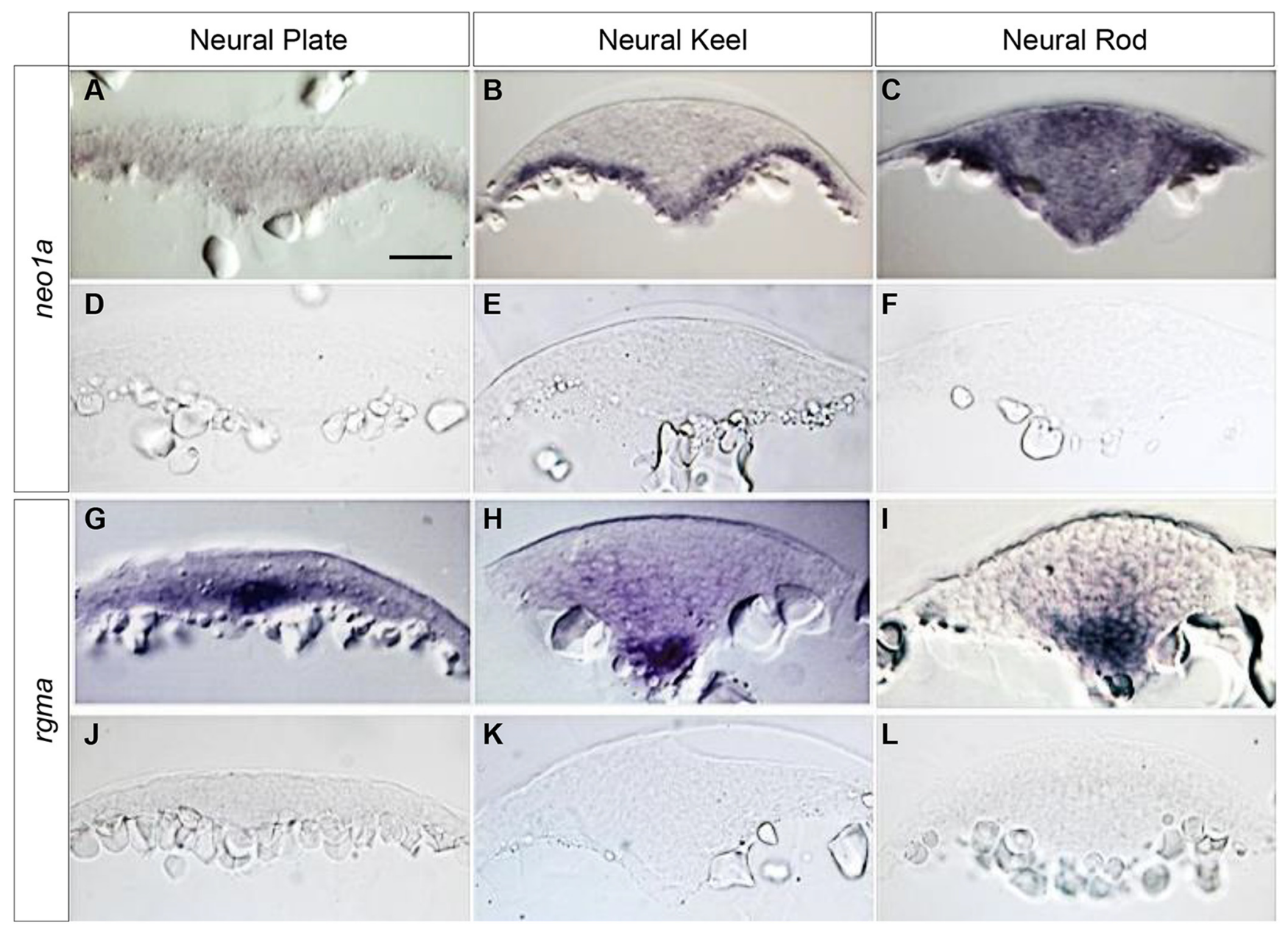

Figure 4. Spatial distribution of zebrafish rgma and neola transcripts during NT development. (ross sections at the hindbrain level of zebrafish embryos at the NP (tailbud; $A, D, G, J)$, neural keel (4-5 som; $\boldsymbol{B}, \boldsymbol{E}, \boldsymbol{H}, \boldsymbol{K})$, and neural $\operatorname{rod}(8-10 \mathrm{som} ; \boldsymbol{C}, \boldsymbol{F}, \boldsymbol{I}, \boldsymbol{L})$ stages labeled by WISH using an antisense neo $1 a$ riboprobe $(\boldsymbol{A}-\boldsymbol{C})$, a sense neo 1 a riboprobe $(\boldsymbol{D}-\boldsymbol{F})$, an rgma antisense riboprobe $(\boldsymbol{G}-\boldsymbol{I})$, and a sense rgma riboprobe $(\boldsymbol{J}-\boldsymbol{L})$. Scale bar, $50 \mu \mathrm{m}$.

8, unpaired two-tailed $t$ test). However, Rgma depletion biased the position of these divisions away from the midline of the neural rod compared with controls (mean percentage of medial cell divisions in control embryos: $100 \pm 0 \mu \mathrm{m}, n=20$ nuclei from 4 embryos; mean percentage of medial cell divisions in rgma MO2injected embryos: $12.08 \pm 9.8 \mu \mathrm{m}, n=26$ nuclei from 6 embryos, $p<0.0001, t=7.178$, df $=8$, unpaired two-tailed $t$ test). Furthermore, the angle of cell division in Rgma-depleted embryos was increased relative to controls (mean angle of division of uninjected controls: $22.43 \pm 4.77^{\circ}, n=20$ nuclei from 4 embryos; mean angle of division of rgma MO2-injected embryos: $40.97 \pm$ $4.44^{\circ}, n=26$ nuclei from 6 embryos, $p=0.0071$ ) (Fig. $7 C$ ). Interestingly, whereas the majority of cell divisions in uninjected control embryos occurred at $\leq 15^{\circ}$ (52\% of divisions in $n=20$ nuclei from 4 control embryos), fewer cell divisions in Rgmadepleted embryos occurred at these angles (15.17\% of divisions in $n=26$ nuclei from 6 rgma MO2-injected embryos, $p=0.0091$, $F_{(5,40)}=3.578$, two-way ANOVA) (Fig. 7C). These findings signify that $\mathrm{C}$ divisions occur at a normal frequency in Rgmadepleted embryos but are positioned away from the midline and their angle of division is oblique to the mediolateral axis of the neural tissue.

To assess whether abnormal $\mathrm{C}$ divisions in embryos defective for Rgma signaling contribute to NT defects (NTDs), we imaged the organization of the NT in hindbrain sections labeled with phalloidin, a marker for filamentous actin (F-actin) that is enriched at the cell cortex and apical pole of NECs (Fig. 8). The $1 \mathrm{dpf}$ control embryos (uninjected) (Fig. 8A) and std MO-injected embryos (data not shown) had a normally shaped NT with a single lumen lined with phalloidin. In contrast, two apical midlines and lumens were observed in severely afflicted embryos depleted of Rgma (rgma MO2-injected and $r g m a^{e x 2-3}$ ) (Fig. 8B,C) or $\mathrm{Neo1a} / \mathrm{b}$ (embryos injected with neo1a MO2 or neo1a $a^{\delta 1133-F L A G}$ ) (Fig. $8 D, E$ ). These findings indicate that, as is observed with mutations in planar cell polarity genes, disruption of RgmaNeola signaling can cause a duplication of the NT.

\section{Rgma-Neo1a signaling is not required for establishing NEC apico-basal polarity}

A previous study by Kee et al. (2008) revealed that depletion of Neo1 causes a dispersal of the tight junction marker zona occludens 1 (ZO1) in the dorsal aspect of the zebrafish neural rod, which led to the conclusion that Rgma-Neo signaling is required for the establishment of apico-basal polarity in NECs (Kee et al., 2008). However, in light of the duplication of the NT we observe in Rgma and Neola knockdown embryos (Fig. $8 B-E$ ), we reexamined this phenotype by analyzing $\mathrm{ZO} 1$ distribution in the neural rod (Fig. 8F,G) and NT (Fig. 8I) of rgma MO2-injected embryos and in the NT of neo1a-MO2 injected embryos (Fig. 8J). We observed that, while ZO1 puncta do indeed seem dispersed 
A
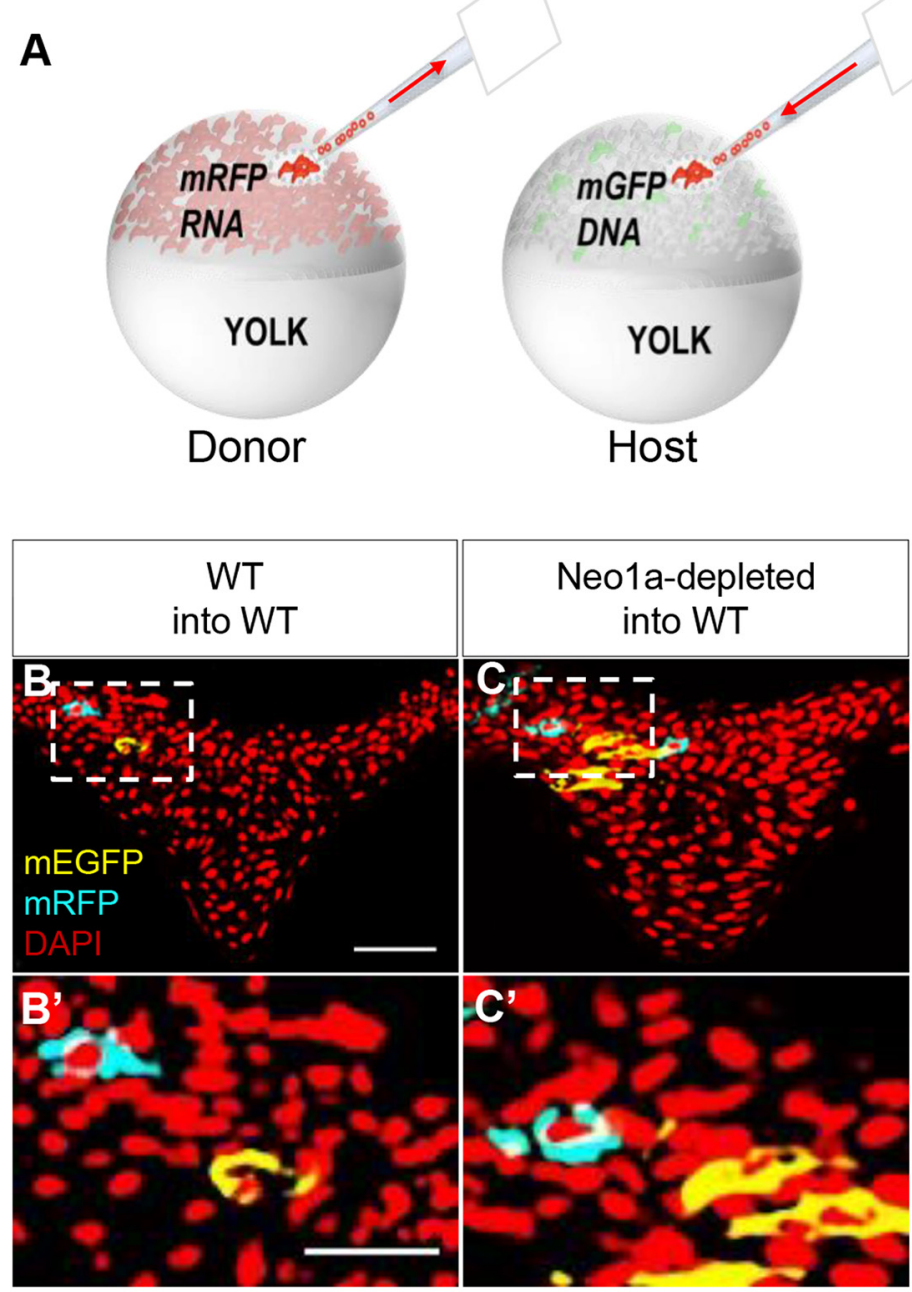

D

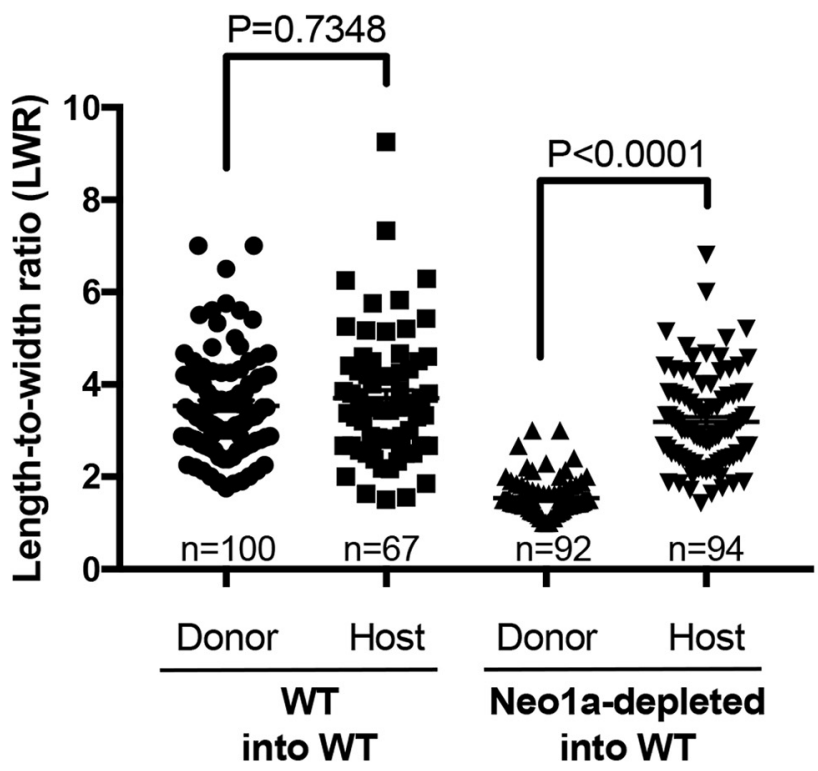

Figure 5. Neo1a functions cell autonomously in the neuroepithelium. $\boldsymbol{A}$, Schematic representation of transplantation to produce chimeras. Cells were taken from the animal pole of shield stage donor embryos labeled with $m R F P$ RNA and transplanted into the animal pole of host embryos at the same developmental stage that were mosaically labeled with mGFP DNA. Red arrows indicate the direction of donor cell movement through the transplantation needle. The host embryos were fixed at $4-5$ som and analyzed for NEC morphology. $\boldsymbol{B}, \boldsymbol{C}$, Transverse sections through the hindbrain of $4-5$ som chimeric embryos. mGFP and mRFP-expressing cells were immunolabeled with anti-GFP (yellow) and anti-RFP (cyan) antibodies, respectively. Nuclei were counterstained with DAPI (red). Scale bar, $50 \mu \mathrm{m} . \boldsymbol{B}^{\prime}-\boldsymbol{C}^{\prime}$, Insets, Higher magnifications of the selected regions and disorganized in the dorsal neural rod of Rgma- and Neo1-depleted embryos, closer examination reveals that ZO1 label indeed forms a "V" shape in the neural rod (8-10 som) (Fig. 8G) that becomes more distinct by $1 \mathrm{dpf}$ (Fig. $8 I, J)$ and is indicative of a duplicated apical midline (Ciruna et al., 2006; Clarke, 2009; Compagnon and Heisenberg, 2013). Together, these observations indicate that RgmaNeola signaling regulates NEC elongation independently of the establishment or maintenance of apical junction markers.

Neo1a and Rgma regulate MT organization during infolding Previous studies from our laboratory and others have demonstrated that MTs and several MT-binding proteins are required for NEC elongation, neural fold elevation, and timely infolding of the NP (Karfunkel, 1971, 1972; Kee et al., 2008; Jayachandran et al., 2016). Furthermore, the Cooper laboratory showed that MTs are disorganized in Xenopus embryos depleted of Neol (Kee et al., 2008). To test whether Rgma and Neol are also required for proper MT organization in zebrafish, we labeled rgma MO2- and neola MO2injected embryos with anti- $\beta$-tubulin at the neural keel stage (4-5 som) (Fig. 9). Interestingly, MTs in these embryos appear shortened and clustered around the nucleus (Fig. 9B-C') compared with the linear arrays observed in control (uninjected) embryos (Fig. 9A, $A^{\prime}$ ), suggesting that Rgma-Neol signaling promotes NEC elongation in an MT-dependent manner.

Full-length Neo1 is consecutively cleaved by $\alpha$ - and $\gamma$-secretase To gain insight into the molecular events activated downstream of Rgma-Neola interaction that promote NEC elongation and infolding, we next investigated whether zebrafish Neol undergoes proteolytic cleavage. A growing list of singlepass (Type I) transmembrane receptors have been shown to undergo regulated intramembrane proteolysis. This process cleaves single-pass (Type I) transmembrane receptors twice: first at the cell surface, which releases the ectodomain into the extracellular space; and then within the

$\leftarrow$

in $\boldsymbol{B}$ and $\boldsymbol{C}$. Scale bar, $25 \mu \mathrm{m}$. D, Quantification of the LWR of donor cells from uninjected controls $(3.54 \pm 0.1 \mu \mathrm{m}, n=100$ cells from 18 embryos) and Neo1a-depleted embryos (1.54 \pm $0.1, n=92$ cells from 9 embryos) and that of their control hosts $(3.70 \pm 0.2, n=67$ cells from 14 embryos and $3.18 \pm$ $0.1, n=94$ cells from 10 embryos, respectively). Data are mean \pm SEM. 
plasma membrane, which solubilizes the ICD (Brown et al., 2000; Marambaud et al., 2002; Gudey et al., 2014; Almagro-Moreno et al., 2015). Consistent with RIP, $\alpha$-secretase (ADAM17)-mediated ectodomain shedding of Neol was previously demonstrated in migrating neurons and regenerating axons (Goldschneider et al., 2008; Okamura et al., 2011; van Erp et al., 2015). Neol is also known to be cleaved by $\gamma$-secretase, an event that releases an intracellular Neol domain (NeoICD) (Goldschneider et al., 2008; van Erp et al., 2015). However, proteolysis of Neol during early embryonic development has not been reported.

To test whether zebrafish Neol is a sheddase substrate, we analyzed protein products of Neol in 1 dpf embryos (when Neol is abundant), in the presence of TAPI-1 $(100 \mu \mathrm{M})$, an inhibitor of ADAM17-like metalloproteases, or vehicle. The proteasome inhibitor MG132 and the nuclear export inhibitor LMB were added to extracts to stabilize short-lived targets of proteasome degradation (Schulte et al., 2007) and retain ADAM17-like proteolytic products in the nucleus, respectively (Goldschneider et al., 2008; Maetzel et al., 2009; Bouillez et al., 2014). Drug treatments were administered from 6 som (neural keel) to 20 som, when protein extracts were harvested. Western blots were performed using anti-Neol that does not distinguish between Neola and Neolb. In presence of vehicle only, we observed Neol fragments of three sizes, 225, 55 , and $40 \mathrm{kDa}$ (Fig. 10A,B). Treatment with TAPI-1 ( $\alpha$-secretase inhibitor) depleted the $55 \mathrm{kDa}$ band and increased the amount of the $225 \mathrm{kDa}$ band (Fig. 10B), suggesting that the $225 \mathrm{kDa}$ protein is a substrate for ADAM17-like metalloproteases. Since ADAM17 proteolytic activity occurs at the juxtamembrane region of its substrates on the outer leaflet of the plasma membrane, we interpret the $55 \mathrm{kDa}$ band to represent a membrane-embedded cleavage product of $\mathrm{Neo} 1$ and the $225 \mathrm{kDa}$ fragment to be full-length Neo1. Our results are consistent with a model in which the Neol ectodomain is shed by an $\alpha$-secretase at the expense of future ligand binding. The $40 \mathrm{kDa}$ band was not altered by TAPI-1 treatment, possibly as a result of its embryonic production before drug treatment and sequestration in the nucleus away from proteases (in the presence of LMB).

We next tested whether the putative $55 \mathrm{kDa} \alpha$-secretase/ ADAM17-like cleavage product is a substrate for $\gamma$-secretase, an intramembrane protease complex. We performed Western blot analysis on lysates derived from 20 som embryos that were treated with DAPT, a $\gamma$-secretase inhibitor, from 6 som to 20 som, in the absence of LMB and MG132 (Fig. 10B) (Jiang et al., 2011; Kalantari et al., 2013). We observed that the relative abundance of the $55 \mathrm{kDa}$ band in the DAPT-treated sample was higher
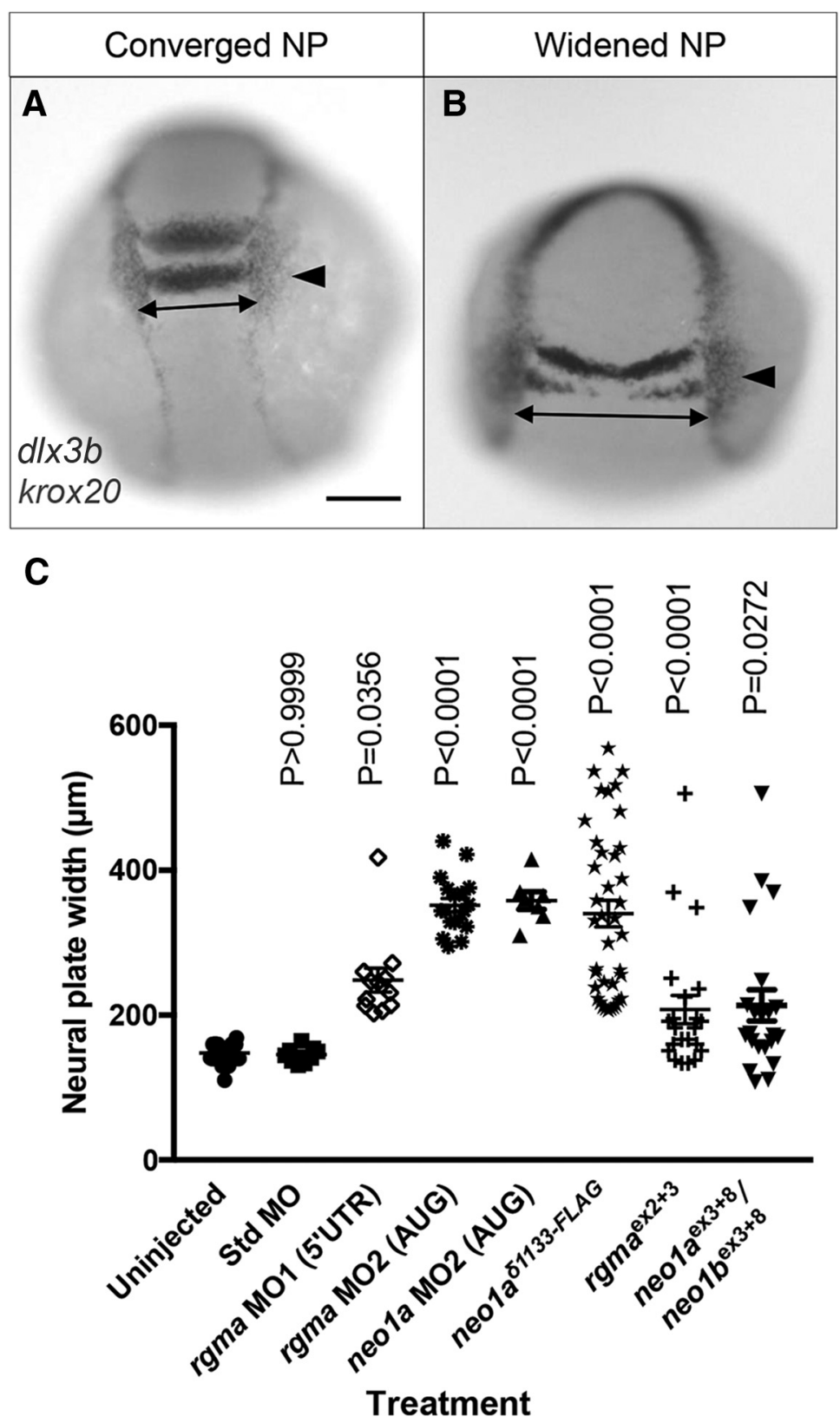

Figure 6. Perturbation of Rgma/Ne01 signaling impairs NP infolding. $\boldsymbol{A}, \boldsymbol{B}$, WISH using $d 1 \times 3$ and krox20 probes on $4-5$ som embryos that underwent timely $(\boldsymbol{A})$ or delayed development $(\boldsymbol{B})$. Arrow indicates lateral edge of krox20-positive rhombomere 5, which coincides with the position of the $d / x 3 b$-positive otic placode. Dotted line indicates NP width measured at the level of rhombomere 5/otic placode. Scale bar, $\sim 75 \mu \mathrm{m}$. $\boldsymbol{C}$, Measurements of NP width (as indicated in $\boldsymbol{A}, \boldsymbol{B}$ ) of uninjected controls and embryos injected with std M0, rgma M01, rgma M02, neo1a M02, neo1a ${ }^{\delta 1133-F L A G}$, rgma gRNA exon $2+3$ and HF-nCas9

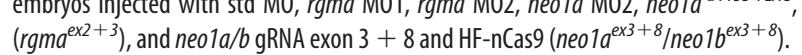

than in the control. The 40 and $225 \mathrm{kDa}$ bands of Neo1 were not resolved under these conditions. These results concur with others suggesting that the $55 \mathrm{kDa} \alpha$-secretase cleavage product of $\mathrm{Neo} 1$ is further processed by $\gamma$-secretase-mediated proteolysis.

Neol is constitutively cleaved during early development To address if and when Neol cleavage is developmentally regulated, we performed Western blot analysis using protein extract from embryos at stages relevant to the process of NP infolding, in the absence of MG132 and LMB. We observed an abundant 55 $\mathrm{kDa}$ band at the tailbud, $4-5 \mathrm{som}$, and 6 som stages (Fig. 10C), which coincide with dynamic morphogenetic movements in all germ layers. The low abundance of the 225 and $40 \mathrm{kDa}$ fragments 

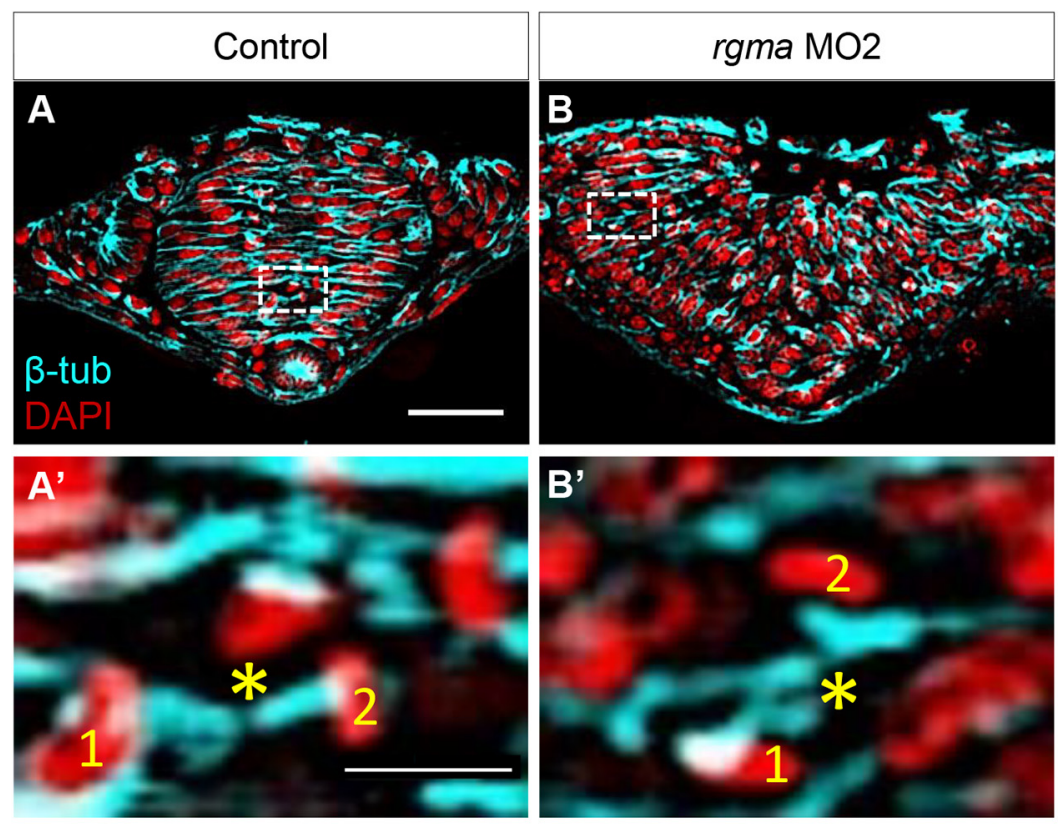

C

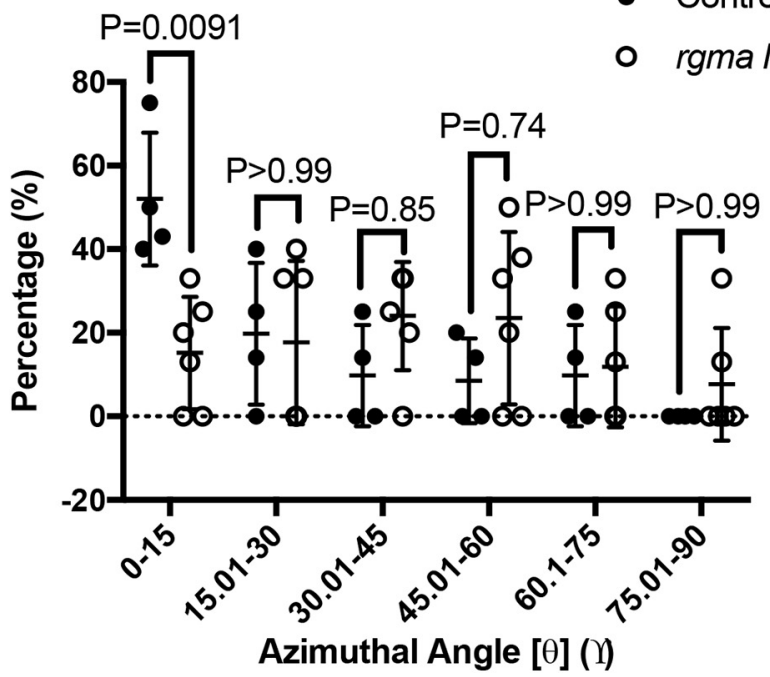

Figure 7. Rgma depletion disrupts ( divisions. $\boldsymbol{A}, \boldsymbol{B}$, Transverse sections through the hindbrain of 8-10 som control (uninjected, $\boldsymbol{A}$ ) and rgma M02-injected $(\boldsymbol{B})$ embryos immunolabeled with anti-tubulin (MTs, cyan) and counterstained with DAPI (nuclei, red). Scale bar, $50 \mu \mathrm{m} . \boldsymbol{A}^{\prime}-\boldsymbol{B}^{\prime}$, Insets, Higher magnification of the boxed regions in $\boldsymbol{A}$ and $\boldsymbol{B}$ showing daughter cells ( 1 and 2) with the estimated position of the midbody $\left({ }^{*}\right)$. Scale bar, $10 \mu \mathrm{m}$. $C$, Percentage of cell divisions occurring at each azimuthal angle $(\theta)$. Control, $n=20$ cell divisions from 4 embryos; rgma M02, $n=26$ cell divisions from 6 embryos.

during early developmental stages suggests that the Neo 1 ectodomain is constitutively shed during early development and that the $\gamma$-secretase cleavage product, NeoICD, is highly unstable (Goldschneider et al., 2008). In contrast, the $40 \mathrm{kDa}$ cleavage product was highly abundant in $5 \mathrm{dpf}$ embryos, even in the absence of LMB (Fig. 10C), suggesting the existence of endogenous mechanisms that stabilize this cleavage product.

\section{Rgma stimulates Neo1 cleavage}

The similarity of the Rgma and Neo1 LOF phenotypes (Figs. 2, 3, $6,8)$ is consistent with these proteins functioning as a ligandreceptor pair during NT development, as reported in other contexts (Mawdsley et al., 2004; Wilson and Key, 2006; Kee et al., 2008). To test whether Neo1 undergoes RIP in response to Rgma binding, we examined Neol proteolytic cleavage in 1 dpf Rgma knockdown embryos using Western blot analysis (Fig. 10D-F). std MO-injected embryos (10 ng) produced the 55 and $40 \mathrm{kDa}$ Neol fragments that are consistent with $\alpha$ - and $\gamma$-secretase processing, respectively (Fig. $10 D$, left lane). In contrast, depletion of Rgma with MO2 (5 and $10 \mathrm{ng}$ ) caused a concentration-dependent reduction in the amount of the 40 and $55 \mathrm{kDa}$ fragments and a corresponding increase in the full-length product range $(225 \mathrm{kDa})$ (Fig. $10 \mathrm{D}$, middle and right lanes, respectively). A similar reduction in the 40 and $55 \mathrm{kDa} \mathrm{Neol}$ fragments is also observed in $\mathrm{rgma}^{\mathrm{ex} 2+3} \mathrm{mu}-$ tants (Fig. 10E, right lane) compared with uninjected controls (Fig. 10E, left lane). These results suggest that Rgma dosedependently regulates the bioavailability of all three specific Neol products, which is consistent with previous observations in cultured cells (Goldschneider et al., 2008; Banerjee et al., 2016). Because the $225 \mathrm{kDa}$ Neol product is low-abundant at $1 \mathrm{dpf}$, we examined an overnight exposure of the blot in Figure $10 D$ and observed this band in all lanes (Fig. 10F, top arrowhead); however, its abundance is much greater in rgma MO2treated samples (Fig. 10F). Interestingly, the overexposed blot also revealed the accumulation of a novel Neo1 band of $\sim 200 \mathrm{kDa}$ that intensified as endogenous Rgma levels decreased (Fig. 10F, bottom arrowhead). This size differential could potentially reflect an additional cleavage event occurring in the absence of Rgma that produces a Neol peptide lacking only the immunoglobulin repeats (Tassew et al., 2014); however, we favor a post-translational modification for the reasons mentioned below.

\section{Neol is N-glycosylated during early development}

Although zebrafish Neola and b paralogs are both estimated to be $\sim 150 \mathrm{kDa}$ in mass based on amino acid sequence, they are often observed at a size $>200 \mathrm{kDa}$ in reducing and denaturing conditions, most likely due to post-translational modifications (PTMs). Bioinformatics approaches have predicted that Neol orthologs in mice, rats, and humans each have 4 disulfide bonds, 6 phosphoserine sites, 2 phosphothreonine sites, and 8 asparagine-linked glycosylation sites. Of these four PTMs, only N-glycosylation is expected to shift the molecular weight of zebrafish Neol sufficiently to account for the 225 and $\sim 200 \mathrm{kDa}$ band sizes (Fig. 10F). This PTM has been linked to the regulation of protein stability, adhesion, and signaling in normal and diseased cells, making it an intriguing candidate for modulating Neol activity during morphogenesis (Eklund and Freeze, 2006; Freeze et al., 2012; Scott and Panin, 2014; Pinho and Reis, 2015; Stowell et al., 2015; Mallard and Tiralongo, 2017); however, in vivo experimental evidence of this Neo1 PTM is limited.

The tripeptide sequence recognized by $\mathrm{N}$-glycosyltransferases, Asn-X-Ser/Th (where X is any residue except proline) is conserved in zebrafish Neol (Cooper et al., 2001). To test whether zebrafish Neo1 is N-glycosylated, we treated $1 \mathrm{dpf}$ embryos 

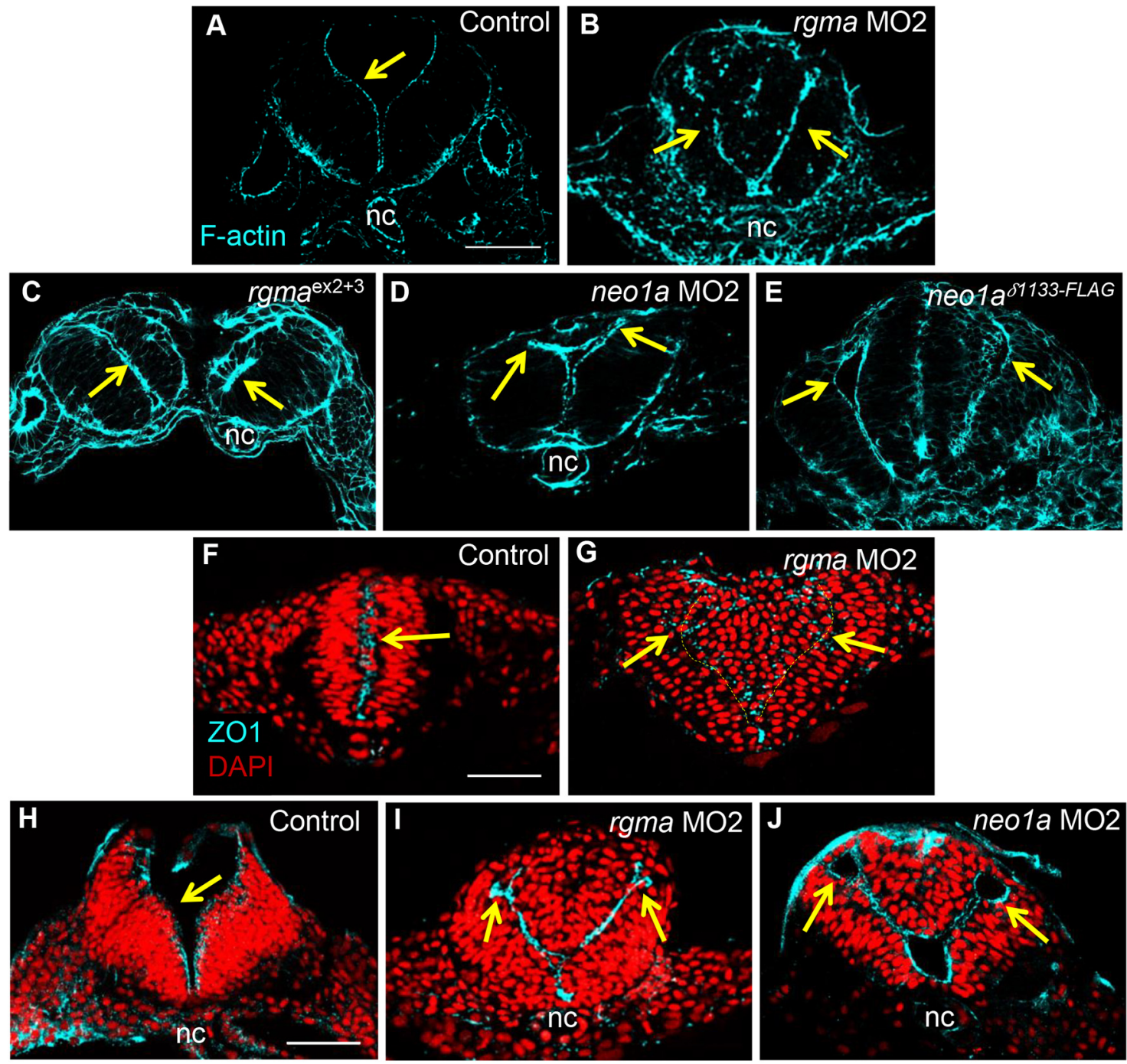

Figure 8. Rgma/Ne01a signaling is not required for junctional polarity establishment or maintenance. $\boldsymbol{A}-\boldsymbol{J}$, Transverse sections through the hindbrain of $1 \mathrm{dpf}(\boldsymbol{A}-\boldsymbol{E}, \boldsymbol{H}-\boldsymbol{J})$ and 12 som $(\boldsymbol{F}, \boldsymbol{G})$ embryos that were untreated $(\boldsymbol{A}, \boldsymbol{F}, \boldsymbol{H})$ or injected with rgma M02-injected $(\boldsymbol{B}, \boldsymbol{G}, \boldsymbol{I})$, rgma gRNA exon $2+3$ and HF-nCas9 $\left(\mathrm{rgma}^{\text {ex2 }+3}\right)$, or neo $1 a^{\text {ס1133-FLAG }}(\boldsymbol{E})$. Embryos were labeled with phalloidin (F-actin, $\boldsymbol{A}-\boldsymbol{E}$, syan) or anti-Z01 (tight junctions, $\boldsymbol{F}-\boldsymbol{J}$, cyan) and counterstained with DAPI (nuclei, $\boldsymbol{F}-\boldsymbol{J}$, red). Arrows indicate the formation of ventricles. nc, Visible notochord. Scale bars, $50 \mu \mathrm{m}$.

with recombinant peptide-N-glycosidase F (PNGaseF), which removes oligosaccharides from asparagine (Asn) residues on glycoproteins (Tarentino et al., 1985) and examined Western blots of lysates. Buffer-treated lysates revealed a $225 \mathrm{kDa}$ Neo 1 peptide (Fig. 10G, left lane), whereas PNGaseF-treated lysates exhibited a downward shift in protein size $(200 \mathrm{kDa}$, Fig. 10G, right lane), suggesting that the full-length peptide is indeed glycosylated and likely to at least partially account for the Neo1 $225 \mathrm{kDa}$ band size.

To directly test whether Rgma regulates Neol glycosylation, we performed an in-gel Fuchsin assay of periodic acid Schiffoxidized glycoproteins using protein extracts from $1 \mathrm{dpf}$ embryos (Fig. 10H) (Roth et al., 2012). We found that Fuchsin labeling of a $\sim 225 \mathrm{kDa}$ protein was reduced in rgma MO2 (5 ng)-injected embryos compared with controls (Fig. 10H). We next probed replicate lanes with anti-Neo1 via Western blot analysis and observed Neo1 immunoreactivity that coincided with the mass of the Fuchsin-positive band. As expected, this $\sim 225 \mathrm{kDa}$ Neo1 band was increased in the Rgma-depleted sample (Fig. 10H). These data suggest that Neol glycosylation is decreased in Rgmadepleted embryos.

\section{NeoICD localizes to the nucleus}

The $40 \mathrm{kDa}$ NeoICD is known to solubilize in an Rgmadependent manner (Goldschneider et al., 2008; van Erp et al., 2015; Banerjee et al., 2016), but its function during embryogenesis is unknown. The conserved $\mathrm{N}$ terminus of the NeoICD includes a nuclear localization signal (Goldschneider et al., 2008), which suggests that this fragment may translocate to the nucleus in the zebrafish embryo. To assess NeoICD distribution, we performed subcellular fractionation on $1 \mathrm{dpf}$ larvae to isolate and purify the nuclear pellet. We found that the $55 \mathrm{kDa}$ Neol fragment was excluded from the nuclear fraction (Fig. 10I, left lane) but present in the supernatant (Fig. 10I, right lane). Instead, the purified nuclear fraction was enriched for the $40 \mathrm{kDa}$ NeoICD (Fig. 10I, left lane). Our results confirm those from studies using human cell culture and chick optic tectum explants, showing that $\gamma$-secretase-mediated Neo1 proteolysis produces a nuclearlocalized soluble cytosolic peptide (Goldschneider et al., 2008; Banerjee et al., 2016). Although the NeoICD was observed at larval stages ( 1 and $5 \mathrm{dpf}$ ), it was undetectable in early embryos in the absence of LMB and MG132 (Fig. 10C), consistent with its 

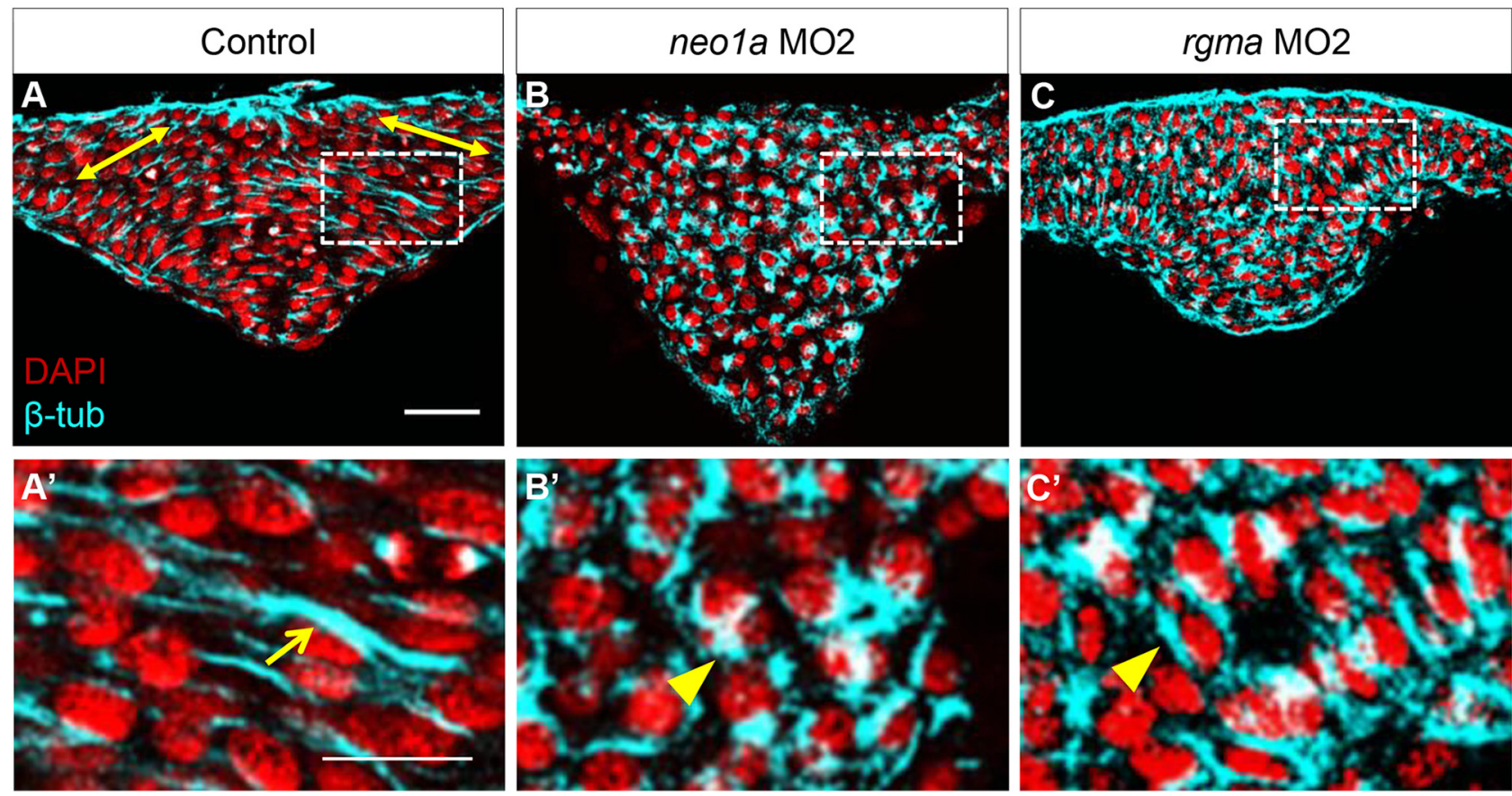

Figure 9. Abnormal MT organization in Neo1a-and Rgma-depleted embryos. $\boldsymbol{A}-\boldsymbol{C}$, Immunofluorescent detection of MTs in transverse hindbrain sections of $4-5$ som control ( $\boldsymbol{A})$, neo $1 a$ M02-injected (B), and rgma M02-injected (C) embryos labeled using anti- $\beta$-tubulin antibodies. Nuclei were counterstained with DAPI (red). Double arrow indicates axis of NEC elongation and radial intercalation. Scale bar, $50 \mu \mathrm{m} . \boldsymbol{A}^{\prime}-\boldsymbol{C}^{\prime}$, Insets, Higher magnification of boxed areas in $\boldsymbol{A}-\boldsymbol{C}$. Arrows indicate elongated MTs. Arrowheads indicate bundled and short MTs. Scale bar, $25 \mu \mathrm{m}$.

previously reported rapid export from the nucleus and degradation (Goldschneider et al., 2008).

\section{NeoICD partially rescues impaired infolding in Neola and Rgma-depleted embryos}

To test the requirement of the NeoICD during infolding, we performed a rescue experiment by injecting 1 cell stage embryos with neo 1 a $\mathrm{MO} 2$ and rgma MO2 in the presence or absence of $50 \mathrm{pg}$ of neola ICD mRNA (neoICD) or neoICD mutant construct (neoICD ${ }^{\text {mut }}$ ) (Fig. 10J) $\left(F_{(7,77)}=64.27, p<0.0001\right.$, ANOVA). Embryos injected with neola MO2 exhibited an abnormally widened NP (414.70 $\pm 28.81 \mu \mathrm{m}, n=8$ embryos) compared with uninjected controls $(123.50 \pm 3.60 \mu \mathrm{m}, n=17$ embryos, $p<$ 0.0001, Tukey test) or neoICD-injected embryos (151.80 \pm 7.89 , $n=17$ embryos, $p<0.0001$, Tukey test). However, when neola $\mathrm{MO} 2$ was coinjected with neoICD, a partial rescue of the NP width (a decrease of $92.07 \pm 20.62 \mu \mathrm{m}$, mean difference \pm SEM difference) was observed in these embryos compared with those injected with neo1a $\mathrm{MO} 2$ alone $(322.60 \pm 15.68 \mu \mathrm{m}, n=9, p=$ 0.0003 , Tukey test).

We next investigated whether NeoICD is sufficient to rescue Rgma LOF. If Rgma-dependent Neo cleavage is important to promote infolding, then NeoICD should rescue the morphological defects in embryos depleted of Rgma. Embryos coinjected with rgma MO2 and neoICD mRNA (50 pg) exhibited a narrower NP $(274.60 \pm 20.08 \mu \mathrm{m}, n=5, p=0.0121$, Tukey test $)$ than embryos injected with rgma MO2 alone (368.90 $\pm 17.83 \mu \mathrm{m}, n=$ $10, p=0.0121$, Tukey test), further supporting the model that Rgma-induced Neo cleavage is required for NT development.

To test whether the translocation of NeoICD into the nucleus is necessary for its function, we generated a zebrafish neoICD mutant construct, neoICD ${ }^{m u t}$, carrying arginine-to-alanine substitutions in the nuclear localization sequence that prevent entry into the nucleus, as reported by Goldschneider et al. (2008). We further found that, in contrast to NeoICD, this mutant form failed to rescue Neo1-depleted embryos $(390.90 \pm 21.07 \mu \mathrm{m}, n=$ $9, p<0.0001$, Tukey test) (Fig. 10J), suggesting that this peptide is required for transcriptional regulation. Although the NP of embryos injected with neoICD ${ }^{\text {mut }}$ alone $(231.40 \pm 15.58 \mu \mathrm{m}, n=$ $10, p=0.0018$, Tukey test) was significantly narrower than that of neo1a MO2-injected embryos, it was wider than that of uninjected embryos, potentially due to the accumulation of NeoICD ${ }^{\text {mut }}$ in the cell causing toxicity. These results suggest a requirement for the NeoICD to promote the process of infolding, as this peptide partially overcomes the effects of Neol and Rgma depletion. The NeoICD has previously been shown to regulate gene transcription, and it is possible that it promotes the expression of genes implicated in cell elongation during NT morphogenesis.

\section{Discussion}

Rgma and Neol promote NEC elongation during infolding Shaping of the NT is dependent on the ability of NECs to elongate; however, the molecular mechanisms underlying this cell behavior are poorly understood. In this study, we provide evidence that NEC elongation is mediated by Rgma-Neola signaling. Using MOs, CRISPR/Cas9 genome-editing tools and DN-Neol (neola ${ }^{\delta 1133-}$ ), we show that disruption of Rgma or Neol causes NECs to adopt an abnormally rounded shape. This defect is, however, transient as cells do eventually elongate (Fig. 8 ), suggesting the existence of compensatory mechanisms.

We further show that depletion of Rgma or Neola impairs infolding, resulting in an abnormally wide NP. Since our cellular analyses were performed at the neural rod stage (when infolding is complete in control embryos), we cannot rule out that the earlier stage of NP narrowing (convergence) is not defective in these embryos. Nevertheless, both processes are dependent on cell elongation and support a central role for Rgma/Neol signaling in promoting this cell behavior. 
A

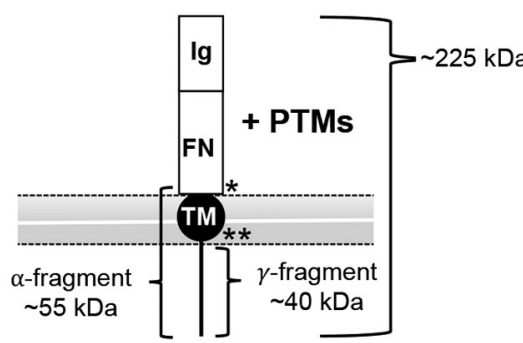

D

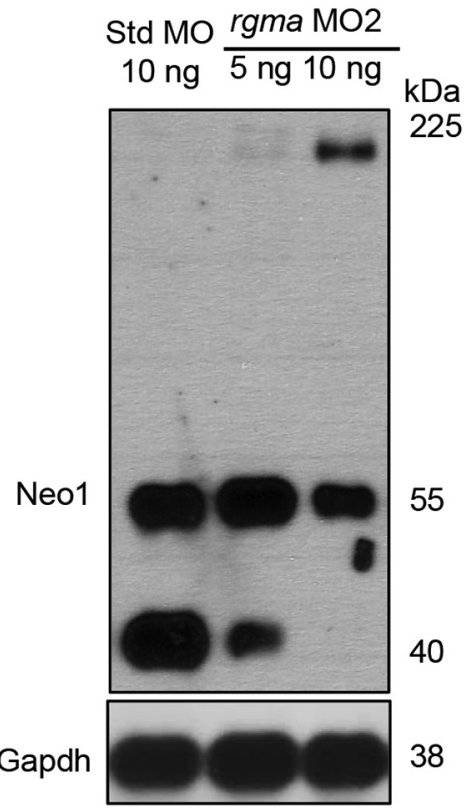

H

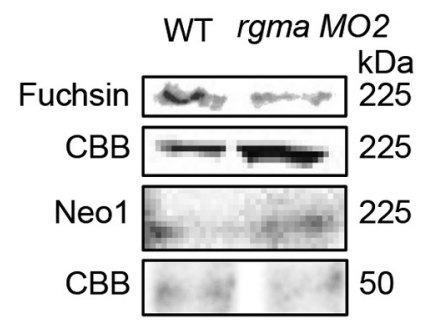

B

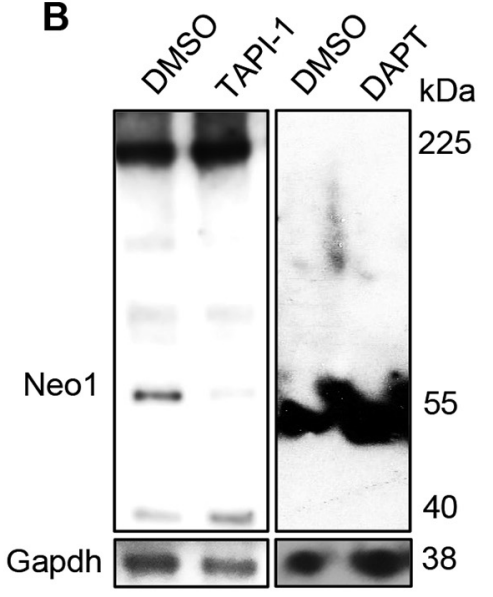

$E$

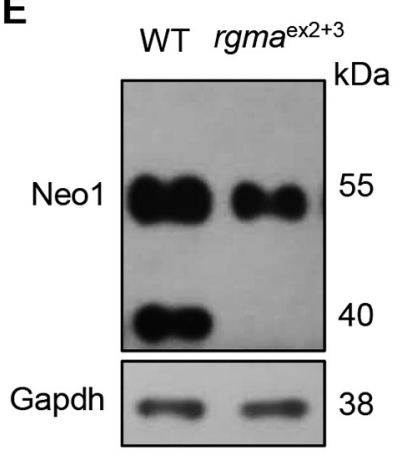

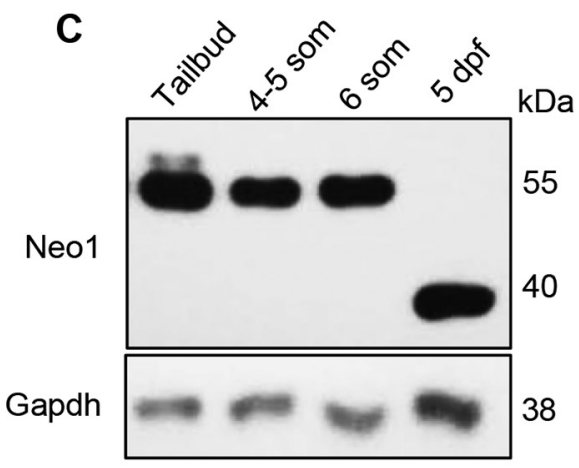

$\mathbf{F}$

Neo1

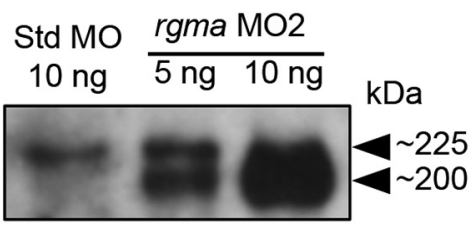

G

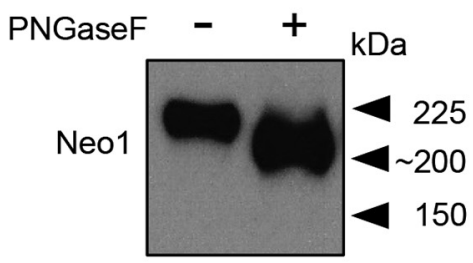

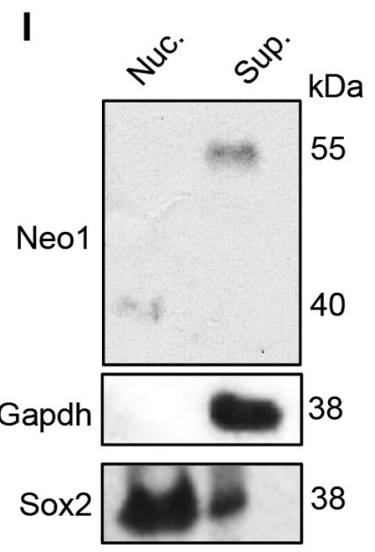

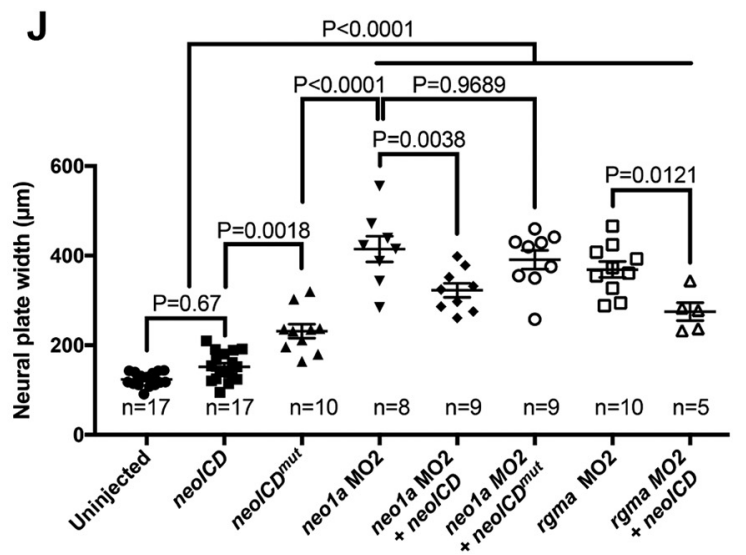

Figure 10. Rgma promotes intramembrane proteolysis of Ne01. A, Diagram of Ne01 embedded in the plasma membrane. Ig, 4 immunoglobulin domains; FN, 6 fibronectin Type III domains; TM, transmembrane domain. ${ }^{*} \alpha$-Secretase/ADAM17 cleavage site. ${ }^{* *} \gamma$-Secretase cleavage site. B, Western blot analysis of Neo1 (Neo1a and Neo1b) protein from embryos treated with DMSO vehicle, $100 \mu \mathrm{m}$ of the $\alpha$-secretase/ADAM17 inhibitor TAPI-1, $8 \mathrm{ng} / \mu$ lof the $\gamma$-secretase inhibitor DAPT in the presence (first two lanes) or absence (last two lanes) of the proteasome and nuclear export inhibitors MG132 and LMB, respectively. C, Western blot analysis of low-molecular weight Ne01 products (55 and $40 \mathrm{kDa}$ ) produced at the tailbud, $4-5$ som, 6 som, and $5 \mathrm{dpf}$ stages. Gapdh is shown as a loading control. $\boldsymbol{D}$, Western blot analysis of endogenous Ne01 levels in protein extract from $24 \mathrm{hpf}$ embryos injected at the 1 cell stage with std M0 (10 ng per embryo, left lane) or rgma M02 (5 and $10 \mathrm{ng}$ per embryo, middle and right lanes, respectively). $\boldsymbol{E}$, Western blot analysis of endogenous Ne01 levels in protein extract from $32 \mathrm{hpf}$ uninjected embryos (left lane) or embryos injected at the 1 cell stage with rgma gRNA exon $2+3$ and HF-nCas 9 (rgma ${ }^{\text {ex2 }+3}$; right lane). $\boldsymbol{F}$, Overnight exposure of the Western blot shown in $\boldsymbol{D}$ revealing the $225 \mathrm{kDa}$ band (top arrowhead) and a second lower molecular weight band (lower arrowhead, $\sim 200 \mathrm{kDa}$ ) in rgma M02 lanes (center and right lanes) but only faintly in the control std M0-injected lane (left lane). The signal intensity of both bands is increased in the rgma M02 lanes. G, Western blot analysis of Ne01 in the absence (left lane) and presence (right lane) of PNGaseF. $\boldsymbol{H}, 0 x i d i z e d$ glycans, total protein, and Ne01 in rgma M02-injected embryos relative to std M0-injected controls detected using in-gel periodic acid Schiff assay, Coomassie staining (CBB), and Western blotting, respectively (see Materials and Methods). I, A fractionated lysate was analyzed by immunoblot using Ne01 antibodies. The purified nuclear fraction (Nuc.) and supernatant (Sup.) are shown in left and right lanes, respectively.J, Width of the NP measured at $4-5$ som in embryos that were uninjected $(123.5 \pm 3.60 \mu \mathrm{m}, n=17)$, injected at the 1 cell stage with $50 \mathrm{pg}$ of neolCD mRNA $(151.8 \pm 7.89, n=17), 50 \mathrm{pg}$ of $n e o l C D^{\text {mut }}(231.40 \pm$ $15.58 \mu \mathrm{m}, n=10), 5 \mathrm{ng}$ neola M02 $(414.7 \pm 28.81 \mu \mathrm{m}, n=8), 5 \mathrm{ng}$ neo $1 a \mathrm{M} 02+50 \mathrm{pg}$ of neolCD mRNA $(322.6 \pm 15.68 \mu \mathrm{m}, n=9), 5 \mathrm{ng}$ neo $1 a \mathrm{M} 02+50 \mathrm{pg}$ of neolCD ${ }^{\text {mut }}(390.90 \pm 21.07$ $\mu \mathrm{m}, n=9), 5 \mathrm{ng}$ of rgma M02 (368.90 $\pm 17.83 \mu \mathrm{m}, n=10)$, and $5 \mathrm{ng}$ rgma M02 $+50 \mathrm{pg}$ of neolCD mRNA $(274.60 \pm 20.08 \mu \mathrm{m}, n=5)$. Data are mean \pm SEM. Statistical significance was determined using Tukey's test. 
Consistent with their role in shaping the NT, both rgma and neol are expressed in the developing NT: rgma more strongly in the midline/floorplate (although also present in the medial aspect of the NT) and neol weakly throughout the neural tissue at the $\mathrm{NP}$ and neural keel stages. Although the expression of neola and $n e o 1 b$ overlap in the NP and keel, depletion of Neola alone causes NTDs, arguing against functional redundancy between these paralogs. Furthermore, while neola transcript is also highly expressed in the paraxial mesoderm (accounting for the axial elongation defects we observe), transplantation of Neola-depleted cells into WT hosts revealed a cell autonomous role for Neol in NEC elongation. Together, these data are consistent with a model whereby Rgma, secreted from the floorplate and/or notochord, binds to Neo1-expressing NECs, thereby promoting their elongation. However, it is also possible that Rgma-Neol interaction occurs in a cis configuration.

\section{Rgma-Neo1 signaling promotes NEC elongation independently of the establishment of apical junctional complexes}

Disruption of convergence and/or infolding of the NP has dramatic and well-documented consequences on later aspects of NT development in zebrafish that are primarily linked to ectopic positioning of $\mathrm{C}$ divisions. We also observe striking NTDs in Rgma- and Neo1-depleted embryos, as evidenced by ectopic (tissue-level) distribution of apical markers ZO1 and phalloidin. In a previous study, the broad distribution of $\mathrm{ZO} 1$ throughout the dorsal aspect of the NT was interpreted as a failure of Neo1depleted cells to establish apico-basal polarity (Kee et al., 2008). However, we propose that ectopic positioning of the apical midline is a more likely explanation and that Rgma-Neol signaling controls NEC elongation independently from the establishment of apical junctional markers. The use of zebrafish in this study was instrumental in making this distinction, as cell elongation and epithelialization are temporally uncoupled in this organism (Hong and Brewster, 2006). It will be interesting in the future to determine whether Rgma-Neo1 signaling and the planar cell polarity pathway converge on common cellular targets to mediate cell elongation.

\section{MT organization is disrupted downstream of Rgma and Neo1 signaling}

In zebrafish, Xenopus, and mice, the MT network undergoes a rapid and dramatic change in organization, which drives cell elongation in the NP. Interphase MTs are initially broadly distributed throughout the cell and randomly oriented. However, they polymerize rapidly, assembling parallel to the long (apicobasal) axis of NECs (Karfunkel, 1971, 1972; Hong and Brewster, 2006; Lee et al., 2007; Cearns et al., 2016). Consistent with a requirement for MTs in NEC elongation, treatment with drugs that either destabilize (vinblastine, colchicine, and nocodazole) or hyperstabilize (paclitaxel) MTs prevents the induction or maintenance of this shape change (Karfunkel, 1971, 1972; Kee et al., 2008; Jayachandran et al., 2016). Morphogenetic movements that are MT-dependent are also perturbed in these drug-treated embryos, including narrowing of the NP and elevation of the neural folds (Karfunkel, 1971, 1972; Kee et al., 2008; Jayachandran et al., 2016). Thus, MT organization is important for both the establishment and maintenance of cell elongation and proper completion of NT morphogenesis. A possible mechanism via which MTs promote cell elongation may be the transport of cytoplasmic materials toward the extending ends of the cell (Burnside, 1971).
MT stability and organization are regulated by binding of MTassociated proteins (Hirokawa, 1994). Post-translational modifications of MT-associated proteins, such as phosphorylation, are thought to modulate their binding affinity to MTs and in turn alter MT stability (Díaz-Nido et al., 1988; Avila et al., 1994; Gordon-Weeks and Fischer, 2000). Deleted in colorectal cancer, a Netrin receptor closely related of Neol triggers phosphorylation of the neural-specific MT-binding protein Maplb upon binding to its ligand (Del Río et al., 2004), raising the interesting possibility that this MT-associated protein may also be activated or transcribed downstream of Neol signaling. In support of this model, we previously reported phenotypes in Map 1b knockdown embryos that are very similar to those observed in Neola- and Rgma-depleted embryos, namely, a widened NP, fully or partially duplicated NTs, failure of NECs to elongate and shortened/disorganized MTs (Jayachandran et al., 2016).

\section{Role of NeoICD and regulation by Rgma}

Using Western blot analysis, we have demonstrated that Rgma stimulates the sequential proteolytic cleavage of zebrafish Neol by an ADAM17-like metalloprotease (van Erp et al., 2015) and $\gamma$-secretase to produce a soluble intracellular fragment, NeoICD. Given the low abundance of full-length Neol throughout early stages of development, we surmise that Rgma induces constitutive Neol ectodomain shedding. These observations are consistent with previous reports revealing that Rgma stimulates ADAM17-mediated Neol ectodomain shedding in differentiated neurons and in the mouse optic tectum (van Erp et al., 2015; Banerjee et al., 2016). Moreover, our subcellular fractionation assay revealed the presence of the zebrafish $40 \mathrm{kDa}$ fragment in the nuclear fraction, similar to a previous report (Goldschneider et al., 2008). This soluble domain is unstable in early-stage embryos and best observed in the presence of proteasome and nuclear export inhibitors, suggesting that NeoICD activity and degradation are tightly regulated.

NeoICD is known to regulate the transcription of several promigratory genes, including cerebral cavernous malformations 2 (CCM2) and grainyhead-like 1 (GRHL1) in human embryonic kidney 293T (HEK293T) and Michigan cancer foundation 7 (MCF-7) human breast cancer cells (Goldschneider et al., 2008). Although it remains unclear whether NeoICD is implicated in the regulation of gene expression in the developing NT, the ability of exogenous NeoICD to partially rescue infolding defects in Neol and Rgma knockdown embryos lends support to the model that proteolytic cleavage of this cell surface receptor is important to promote NT morphogenesis. Of particular relevance is the finding that Rgma induces the release of the transcriptional coactivator LIM domain only 4 (LMO4) from the cytoplasmic tail of Neo1. After nuclear entry, LMO4 is proposed to modulate the transcriptional activity of mediators of neuronal outgrowth (Schaffar et al., 2008). It is currently unclear whether Rgma-Neo1-dependent transcriptional responses originate from NeoICD or LMO4, which rely on an endogenous nuclear localization sequence domain or bind to nuclear LIM interactor to translocate into the nucleus, respectively (Kenny et al., 1998). These observations provide a rationale for future work to identify targets downstream of the RgmaNeol interaction that shape the NT, via transcriptional regulation or otherwise (Babitt et al., 2005; Hata et al., 2006; Conrad et al., 2007; Zhou et al., 2010; Tian and Liu, 2013). 


\section{$\mathrm{N}$-glycosylation of NeoICD}

The N-glycosylation events that we report for full-length Neol provide more evidence that the Neol biosynthetic pathway is conserved in zebrafish (Meyerhardt et al., 1997; Vielmetter et al., 1997; Kleene and Schachner, 2004; Liu et al., 2005; Wollscheid et al., 2009). Interestingly, Rgma depletion reduces the molecular mass of Neo 1 from 225 to $200 \mathrm{kDa}$, which is consistent with Neo1 deglycosylation. These data suggest that Rgma promotes the retention of this PTM once Neol is inserted in the plasma membrane, although other models are possible. The functional significance of Neol glycosylation is unclear, but it is tempting to speculate that it could be linked to the regulation of its proteolytic cleavage.

Overall, this study reveals that Rgma-Neo1 signaling regulates cell elongation during neurulation independently of the establishment of apical junctional complexes and identifies Neol proteolysis as an early signaling event downstream of ligandreceptor interactions in the developing embryo. The proposed function of Rgma/Neol signaling is likely to be conserved in vertebrates, as rgma LOF in Xenopus and mouse embryos causes severe NTDs (Niederkofler et al., 2004; Kee et al., 2008). Future work identifying the transcriptional targets of the NeoICD is likely to provide novel insights into the molecular mechanisms that regulate NEC elongation during neurulation. It would also be of interest to determine whether the other Neol cleavage products, the shed ectodomain and the membrane-embedded $55 \mathrm{kDa}$ fragment, play a regulatory role during neural development.

\section{References}

Almagro-Moreno S, Kim TK, Skorupski K, Taylor RK (2015) Proteolysis of virulence regulator ToxR is associated with entry of Vibrio cholerae into a dormant state. PLoS Genet 11:e1005145.

Anderson JL, Mulligan TS, Shen MC, Wang H, Scahill CM, Tan FJ, Du SJ, Busch-Nentwich EM, Farber SA (2017) mRNA processing in mutant zebrafish lines generated by chemical and CRISPR-mediated mutagenesis produces unexpected transcripts that escape nonsense-mediated decay. PLOS Genet 13:e1007105.

Andersson M, Turesson H, Olsson N, Fält AS, Ohlsson P, Gonzalez MN, Samuelsson M, Hofvander P (2018) Genome editing in potato via CRISPR-Cas9 ribonucleoprotein delivery. Physiol Plant 164:378-384.

Avila J, Domínguez J, Díaz-Nido J (1994) Regulation of microtubule dynamics by microtubule-associated protein expression and phosphorylation during neuronal development. Int J Dev Biol 38:13-25.

Babitt JL, Zhang Y, Samad TA, Xia Y, Tang J, Campagna JA, Schneyer AL, Woolf CJ, Lin HY (2005) Repulsive guidance molecule (RGMa), a DRAGON homologue, is a bone morphogenetic protein co-receptor. J Biol Chem 280:29820-29827.

Banerjee P, Harada H, Tassew NG, Charish J, Goldschneider D, Wallace VA, Sugita S, Mehlen P, Monnier PP (2016) $\gamma$-Secretase and LARG mediate distinct RGMa activities to control appropriate layer targeting within the optic tectum. Cell Death Differ 23:442-453.

Bill BR, Petzold AM, Clark KJ, Schimmenti LA, Ekker SC (2009) A primer for morpholino use in zebrafish. Zebrafish 6:69-77.

Bouillez A, Gnemmi V, Gaudelot K, Hémon B, Ringot B, Pottier N, Glowacki F, Butruille C, Cauffiez C, Hamdane M, Sergeant N, Van Seuningen I, Leroy X, Aubert S, Perrais M (2014) MUC1-C nuclear localization drives invasiveness of renal cancer cells through a sheddase/gamma secretase dependent pathway. Oncotarget 5:754-763.

Brown MS, Ye J, Rawson RB, Goldstein JL (2000) Regulated intramembrane proteolysis: a control mechanism conserved from bacteria to humans. Cell 100:391-398.

Burger A, Lindsay H, Felker A, Hess C, Anders C, Chiavacci E, Zaugg J, Weber LM, Catena R, Jinek M, Robinson MD, Mosimann C (2016) Maximizing mutagenesis with solubilized CRISPR-Cas9 ribonucleoprotein complexes. Development 143:2025-2037.

Burnside B (1971) Microtubules and microfilaments in newt neuralation. Dev Biol 26:416-441.
Cearns MD, Escuin S, Alexandre P, Greene ND, Copp AJ (2016) Microtubules, polarity and vertebrate neural tube morphogenesis. J Anat 229:63-74.

Ciruna B, Jenny A, Lee D, Mlodzik M, Schier AF (2006) Planar cell polarity signalling couples cell division and morphogenesis during neurulation. Nature 439:220-224.

Clarke J (2009) Role of polarized cell divisions in zebrafish neural tube formation. Curr Opin Neurobiol 19:134-138.

Colas JF, Schoenwolf GC (2001) Towards a cellular and molecular understanding of neurulation. Dev Dyn 221:117-145.

Compagnon J, Heisenberg CP (2013) Neurulation: coordinating cell polarisation and lumen formation. EMBO J 32:1-3.

Conant GC, Wagner A (2004) Duplicate genes and robustness to transient gene knock-downs in Caenorhabditis elegans. Proc Biol Sci 271:89-96.

Conrad S, Genth H, Hofmann F, Just I, Skutella T (2007) Neogenin-RGMa signaling at the growth cone is bone morphogenetic protein-independent and involves RhoA, ROCK, and PKC. J Biol Chem 282:16423-16433.

Cooper CA, Gasteiger E, Packer NH (2001) GlycoMod: a software tool for determining glycosylation compositions from mass spectrometric data. Proteomics 1:340-349.

Davidson LA, Keller RE (1999) Neural tube closure in Xenopus laevis involves medial migration, directed protrusive activity, cell intercalation and convergent extension. Development 126:4547-4556.

Del Río JA, González-Billault C, Ureña JM, Jiménez EM, Barallobre MJ, Pascual M, Pujadas L, Simó S, La Torre A, Wandosell F, Avila J, Soriano E (2004) MAP1B is required for netrin 1 signaling in neuronal migration and axonal guidance. Curr Biol 14:840-850.

Díaz-Nido J, Serrano L, Méndez E, Avila J (1988) A casein kinase II-related activity is involved in phosphorylation of microtubule-associated protein MAP-1B during neuroblastoma cell differentiation. J Cell Biol 106: 2057-2065.

Eisen JS, Smith JC (2008) Controlling morpholino experiments: don't stop making antisense. Development 135:1735-1743.

Enns CA, Ahmed R, Zhang AS (2012) Neogenin interacts with matriptase-2 to facilitate hemojuvelin cleavage. J Biol Chem 287:35104-35117.

Eklund EA, Freeze HH (2006) The congenital disorders of glycosylation: a multifaceted group of syndromes. NeuroRx 3:254-263.

Freeze HH, Eklund EA, Ng BG, Patterson MC (2012) Neurology of inherited glycosylation disorders. Lancet Neurol 11:453-466.

Geldmacher-Voss B, Reugels AM, Pauls S, Campos-Ortega JA (2003) A $90^{\circ}$ rotation of the mitotic spindle changes the orientation of mitoses of zebrafish neuroepithelial cells. Development 130:3767-3780.

Gibert Y, Lattanzi VJ, Zhen AW, Vedder L, Brunet F, Faasse SA, Babitt JL, Lin HY, Hammerschmidt M, Fraenkel PG (2011) BMP signaling modulates hepcidin expression in zebrafish embryos independent of hemojuvelin. PLoS One 6:e14553.

Goldschneider D, Rama N, Guix C, Mehlen P (2008) The neogenin intracellular domain regulates gene transcription via nuclear translocation. Mol Cell Biol 28:4068-4079.

Gordon-Weeks PR, Fischer I (2000) MAP1B expression and microtubule stability in growing and regenerating axons. Microsc Res Tech 48:63-74.

Gu Z, Steinmetz LM, Gu X, Scharfe C, Davis RW, Li WH (2003) Role of duplicate genes in genetic robustness against null mutations. Nature 421: 63-66.

Gudey SK, Wallenius A, Landström M (2014) Regulated intramembrane proteolysis of the TGF $\beta$ type I receptor conveys oncogenic signals. Future Oncol 10:1853-1861.

Hanada K, Sawada Y, Kuromori T, Klausnitzer R, Saito K, Toyoda T, Shinozaki K, Li WH, Hirai MY (2011) Functional compensation of primary and secondary metabolites by duplicate genes in arabidopsis thaliana. Mol Biol Evol 28:377-382.

Hartman JL 4th, Garvik B, Hartwell L (2001) Principles for the buffering of genetic variation. Science 291:1001-1004.

Hata K, Fujitani M, Yasuda Y, Doya H, Saito T, Yamagishi S, Mueller BK, Yamashita T (2006) RGMa inhibition promotes axonal growth and recovery after spinal cord injury. J Cell Biol 173:47-58.

Hirokawa N (1994) Microtubule organization and dynamics dependent on microtubule-associated proteins. Curr Opin Cell Biol 6:74-81.

Hong E, Brewster R (2006) N-cadherin is required for the polarized cell behaviors that drive neurulation in the zebrafish. Development 133:38953905. 
Jayachandran P, Hong E, Brewster R (2010) Labeling and imaging cells in the zebrafish hindbrain. J Vis Exp 41:1976.

Jayachandran P, Olmo VN, Sanchez SP, McFarland RJ, Vital E, Werner JM, Hong E, Sanchez-Alberola N, Molodstov A, Brewster RM (2016) Microtubule-associated protein $1 \mathrm{~b}$ is required for shaping the neural tube. Neural Dev 11:1.

Jiang LY, Zhang XL, Du P, Zheng JH (2011) $\gamma$-Secretase inhibitor, DAPT inhibits self-renewal and stemness maintenance of ovarian cancer stemlike cells in vitro. Chin J Cancer Res 23:140-146.

Kalantari E, Saeidi H, Kia NS, Tahergorabi Z, Rashidi B, Dana N, Khazaei M (2013) Effect of DAPT, a gamma secretase inhibitor, on tumor angiogenesis in control mice. Adv Biomed Res 2:83.

Karfunkel P (1971) The role of microtubules and microfilaments in neurulation in Xenopus. Dev Biol 25:30-56.

Karfunkel P (1972) The activity of microtubules and microfilaments in neurulation in the chick. J Exp Zool 181:289-301.

Karfunkel P (1974) The mechanisms of neural tube formation. Int Rev Cytol 38:245-271.

Kee N, Wilson N, De Vries M, Bradford D, Key B, Cooper HM (2008) Neogenin and RGMa control neural tube closure and neuroepithelial morphology by regulating cell polarity. J Neurosci 28:12643-12653.

Kemp HA, Carmany-Rampey A, Moens C (2009) Generating chimeric zebrafish embryos by transplantation. J Vis Exp 29:1394.

Kenny DA, Jurata LW, Saga Y, Gill GN (1998) Identification and characterization of LMO4, an LMO gene with a novel pattern of expression during embryogenesis. Proc Natl Acad Sci U S A 95:11257-11262.

Kim S, Kim D, Cho SW, Kim J, Kim JS (2014) Highly efficient RNA-guided genome editing in human cells via delivery of purified Cas9 ribonucleoproteins. Genome Res 24:1012-1019.

Kimmel CB, Ballard WW, Kimmel SR, Ullmann B, Schilling TF (1995) Stages of embryonic development of the zebrafish. Dev Dyn 203:253-310.

Kleene R, Schachner M (2004) Glycans and neural cell interactions. Nat Rev Neurosci 5:195-208.

Labun K, Montague TG, Gagnon JA, Thyme SB, Valen E (2016) CHOPCHOP v2: a web tool for the next generation of CRISPR genome engineering. Nucleic Acids Res 44:W272-W276.

Lee C, Scherr HM, Wallingford JB (2007) Shroom family proteins regulate $\gamma$-tubulin distribution and microtubule architecture during epithelial cell shape change. Development 134:1431-1441.

Li S, Li Z, Shu FJ, Xiong H, Phillips AC, Dynan WS (2014) Double-strand break repair deficiency in NONO knock-out murine embryonic fibroblasts and compensation by spontaneous upregulation of the PSPC1 paralog. Nucleic Acids Res 42:9771-9780.

Liu T, Qian WJ, Gritsenko MA, Camp DG 2nd, Monroe ME, Moore RJ, Smith RD (2005) Human plasma N-glycoproteome analysis by immunoaffinity subtraction, hydrazide chemistry, and mass spectrometry. J Proteome Res 4:2070-2080.

Lowery LA, Sive H (2004) Strategies of vertebrate neurulation and a reevaluation of teleost neural tube formation. Mech Dev 121:1189-1197.

Maetzel D, Denzel S, Mack B, Canis M, Went P, Benk M, Kieu C, Papior P, Baeuerle PA, Munz M, Gires O (2009) Nuclear signalling by tumourassociated antigen EpCAM. Nat Cell Biol 11:162-171.

Mallard BW, Tiralongo J (2017) Cancer stem cell marker glycosylation: nature, function and significance. Glycoconj J 34:441-452.

Marambaud P, Shioi J, Serban G, Georgakopoulos A, Sarner S, Nagy V, Baki L, Wen P, Efthimiopoulos S, Shao Z, Wisniewski T, Robakis NK (2002) A presenilin-1/gamma-secretase cleavage releases the E-cadherin intracellular domain and regulates disassembly of adherens junctions. EMBO J 21:1948-1956.

Marsden M, DeSimone DW (2001) Regulation of cell polarity, radial intercalation and epiboly in Xenopus: novel roles for integrin and fibronectin. Development 128:3635-3647.

Mawdsley DJ, Cooper HM, Hogan BM, Cody SH, Lieschke GJ, Heath JK (2004) The netrin receptor neogenin is required for neural tube formation and somitogenesis in zebrafish. Dev Biol 269:302-315.

Megason SG, Fraser SE (2003) Digitizing life at the level of the cell: highperformance laser-scanning microscopy and image analysis for in toto imaging of development. Mech Dev 120:1407-1420.

Meeker ND, Hutchinson SA, Ho L, Trede NS (2007) Method for isolation of PCR-ready genomic DNA from zebrafish tissues. Biotechniques 43:610, 612,614 .

Meyerhardt JA, Look AT, Bigner SH, Fearon ER (1997) Identification and characterization of neogenin, a DCC-related gene. Oncogene 14:11291136.

Montague TG, Cruz JM, Gagnon JA, Church GM, Valen E (2014) CHOPCHOP: a CRISPR/Cas9 and TALEN web tool for genome editing. Nucleic Acids Res 42:W401-407.

Moulton JD (2017) Making a morpholino experiment work: controls, favoring specificity, improving efficacy, storage, and dose: morpholino oligomers. In: Methods in molecular biology, pp 17-29. New York: Humana.

Nasevicius A, Ekker SC (2000) Effective targeted gene "knockdown" in zebrafish. Nat Genet 26:216-220.

Niederkofler V, Salie R, Sigrist M, Arber S (2004) Repulsive guidance molecule (RGM) gene function is required for neural tube closure but not retinal topography in the mouse visual system. J Neurosci 24:808-818.

Oda H, Sato T, Kunishima S, Nakagawa K, Izawa K, Hiejima E, Kawai T, Yasumi T, Doi H, Katamura K, Numabe H, Okamoto S, Nakase H, Hijikata A, Ohara O, Suzuki H, Morisaki H, Morisaki T, Nunoi H, Hattori S, et al. (2016) Exon skipping causes atypical phenotypes associated with a loss-of-function mutation in FLNA by restoring its protein function. Eur J Hum Genet 24:408-414.

Okamura Y, Kohmura E, Yamashita T (2011) TACE cleaves neogenin to desensitize cortical neurons to the repulsive guidance molecule. Neurosci Res 71:63-70.

Papan C, Campos-Ortega JA (1994) On the formation of the neural keel and neural tube in the zebrafish danio (Brachydanio) rerio. Roux Arch Dev Biol 203:178-186.

Peng CH, Lin SH, Peng SC, Lyu PC, Arita M, Tang CY (2012) Feature identification of compensatory gene pairs without sequence homology in yeast. Comp Funct Genomics 2012:653174.

Pinho SS, Reis CA (2015) Glycosylation in cancer: mechanisms and clinical implications. Nat Rev Cancer 15:540-555.

Roth Z, Yehezkel G, Khalaila I (2012) Identification and quantification of protein glycosylation. Int J Carbohydrate Chem 2012:640923.

Schaffar G, Taniguchi J, Brodbeck T, Meyer AH, Schmidt M, Yamashita T, Mueller BK (2008) LIM-only protein 4 interacts directly with the repulsive guidance molecule A receptor neogenin. J Neurochem 107: $418-431$.

Schmajuk G, Sierakowska H, Kole R (1999) Antisense oligonucleotides with different backbones: modification of splicing pathways and efficacy of uptake. J Biol Chem 274:21783-21789.

Schoenwolf GC, Franks MV (1984) Quantitative analyses of changes in cell shapes during bending of the avian neural plate. Dev Biol 105:257272.

Schroeder TE (1970) Neurulation in Xenopus laevis: an analysis and model based upon light and electron microscopy. J Embryol Exp Morphol 23: 427-462.

Schulte A, Schulz B, Andrzejewski MG, Hundhausen C, Mletzko S, Achilles J, Reiss K, Paliga K, Weber C, John SR, Ludwig A (2007) Sequential processing of the transmembrane chemokines CX3CL1 and CXCL16 by $\alpha-$ and $\gamma$-secretases. Biochem Biophys Res Commun 358:233-240.

Scott H, Panin VM (2014) N-glycosylation in regulation of the nervous system. Adv Neurobiol 9:367-394.

Sharpe JJ, Cooper TA (2017) Unexpected consequences: exon skipping caused by CRISPR-generated mutations. Genome Biol 18:109.

Shen H, Illges H, Reuter A, Stuermer CA (2002) Cloning, expression, and alternative splicing of neogenin 1 in zebrafish. Mech Dev 118:219 223

Shum AS, Copp AJ (1996) Regional differences in morphogenesis of the neuroepithelium suggest multiple mechanisms of spinal neurulation in the mouse. Anat Embryol 194:65-73.

Stainier DY, Raz E, Lawson ND, Ekker SC, Burdine RD, Eisen JS, Ingham PW, Schulte-Merker S, Yelon D, Weinstein BM, Mullins MC, Wilson SW, Ramakrishnan L, Amacher SL, Neuhauss SC, Meng A, Mochizuki N, Panula P, Moens CB (2017) Guidelines for morpholino use in zebrafish. PLoS Genet 13:e1007000.

Stowell SR, Ju T, Cummings RD (2015) Protein glycosylation in cancer. Annu Rev Pathol 10:473-510.

Suzuki M, Morita H, Ueno N (2012) Molecular mechanisms of cell shape changes that contribute to vertebrate neural tube closure. Dev Growth Differ 54:266-276.

Sztal TE, McKaige EA, Williams C, Ruparelia AA, Bryson-Richardson RJ (2018) Genetic compensation triggered by actin mutation prevents 
the muscle damage caused by loss of actin protein. PLOS Genet 14:e1007212.

Tarentino AL, Gomez CM, Plummer TH Jr (1985) Deglycosylation of asparagine-linked glycans by peptide:N-glycosidase F. Biochemistry 24:4665-4671.

Tassew NG, Charish J, Seidah NG, Monnier PP (2012) SKI-1 and furin generate multiple RGMa fragments that regulate axonal growth. Dev Cell 22:391-402.

Tassew NG, Mothe AJ, Shabanzadeh AP, Banerjee P, Koeberle PD, Bremner R, Tator CH, Monnier PP (2014) Modifying lipid rafts promotes regeneration and functional recovery. Cell Rep 8:1146-1159.

Tawk M, Araya C, Lyons DA, Reugels AM, Girdler GC, Bayley PR, Hyde DR, Tada M, Clarke JD (2007) A mirror-symmetric cell division that orchestrates neuroepithelial morphogenesis. Nature 446:797-800.

Thisse B, Pflumio S, Fürthauer M, Loppin B, Heyer V, Degrave A, Woehl R, Lux A, Steffan T, Charbonnier XQ, Thisse C (2001) Expression of the zebrafish genome during embryogenesis (National Institutes of Health R01 RR15402). Bethesda, MD: National Institutes of Health.

Thisse C, Thisse B (2008) High-resolution in situ hybridization to wholemount zebrafish embryos. Nat Protocols 3:59-69.

Tian C, Liu J (2013) Repulsive guidance molecules (RGMs) and neogenin in bone morphogenetic protein (BMP) signaling. Mol Reprod Dev 80: $700-717$.

To B, Andrechek ER (2018) Transcription factor compensation during mammary gland development in E2F knockout mice. PLoS One 13:e0194937.
Topczewski J, Solnica-Krezel L (1999) Cytoskeletal dynamics of the zebrafish embryo. Methods Cell Biol 59:205-226.

Tran LD, Hino H, Quach H, Lim S, Shindo A, Mimori-Kiyosue Y, Mione M, Ueno N, Winkler C, Hibi M, Sampath K (2012) Dynamic microtubules at the vegetal cortex predict the embryonic axis in zebrafish. Development 139:3644-3652.

van Erp S, van den Heuvel DM, Fujita Y, Robinson RA, Hellemons AJ, Adolfs Y, Van Battum EY, Blokhuis AM, Kuijpers M, Demmers JA, Hedman H, Hoogenraad CC, Siebold C, Yamashita T, Pasterkamp RJ (2015) Lrig2 negatively regulates ectodomain shedding of axon guidance receptors by ADAM proteases. Dev Cell 35:537-552.

Vielmetter J, Chen XN, Miskevich F, Lane RP, Yamakawa K, Korenberg JR, Dreyer WJ (1997) Molecular characterization of human neogenin, a DCC-related protein, and the mapping of its gene (NEO1) to chromosomal position 15q22.3-q23. Genomics 41:414-421

Wilson NH, Key B (2006) Neogenin interacts with RGMa and netrin-1 to guide axons within the embryonic vertebrate forebrain. Dev Biol 296:485-498.

Wollscheid B, Bausch-Fluck D, Henderson C, O’Brien R, Bibel M, Schiess R, Aebersold R, Watts JD (2009) Mass-spectrometric identification and relative quantification of $\mathrm{N}$-linked cell surface glycoproteins. Nat Biotechnol 27:378-386.

Zhou Z, Xie J, Lee D, Liu Y, Jung J, Zhou L, Xiong S, Mei L, Xiong WC (2010) Neogenin regulation of BMP-induced canonical smad signaling and endochondral bone formation. Dev Cell 19:90-102. 